NBER WORKING PAPER SERIES

\title{
ADJUSTING OUTPUT AND PRODUCTIVITY \\ INDEXES FOR CHANGES IN \\ THE TERMS OF TRADE
}

W. Erwin Diewert

Catherine J. Morrison

Working Paper No. 1564

\author{
NATIONAL BUREAU OF ECONOMIC RESEARCH \\ 1050 Massachusetts Avenue \\ Cambridge, MA 02138 \\ February 1985
}

The research reported here is part of the NBER's research program in Productivity and project in Productivity and Industrial Change in the World Economy. Any opinions expressed are those of the authors and not those of the National Bureau of Economic Research. 


\author{
Adjusting Output and Productivity \\ Indexes for Changes in \\ the Terms of Trade
}

\title{
ABS TRACT
}

In this paper we employ index number theory in addressing the problem of adjusting real national income and real domestic product for changes in a country's terms of trade. More specifically, using recent developments in the theory of production, we address the problems related to measuring: (i) real output produced and real input utilized by the private business sector; (ii) productivity growth or technical change; (iii) the effects on domestic real output of changes in the terms of trade; and (iv) the impact on final sales to domestic purchasers of changes in the balance of payments deficit, in a consistent accounting framework.

This treatment of international trade allows us to undertake comparative statics analyses using only production theory, whereas in the traditional paradigm which treats traded goods as perfectly substitutable with a class of domestic goods, a general equilibrium framework is required. We illustrate our suggested solutions using U.S. data for the years 1968-82.

W. Erwin Diewert Department of Economics University of British Columbia Vancouver, BC V6T 1 Y 2 Canada
Catherine J. Morrison

National Bureau of

Economic Research 204 Junipero Serra B1vd. Stanford, CA 94305 
Adjusting Output and Productivity Indexes for Changes in the Terms of Trade W. Erwin Diewert

and

Catherine J. Morrison

1. Introduction

For many years, national income accountants have attempted to measure the effects of terms of trade changes on national welfare. More recently, the terms of tradel adjustment issue has been approached from the viewpoint of economic theory and welfare economics by Svenson and Razin [1983], Lloyd and Schwelnberger [1983], Greenlees and Zieschang [1984], and Hamada and Iwata [1984]. These authors treat the terms of trade adjustment issue by considering the effects on a single consumer or by using a community utility function. Both of these approaches involve difficult problems of aggregation over consumers.

Our alternative approach to the measurement of the impact of terms of trade changes is to consider the problem from the point of view of the producer. In this alternative approach, our objective function becomes real output rather than welfare. We assume that exports and imports flow through the production sector and we show that an increase in the price of exports relative to imports has an effect that is similar to an increase in total factor productivity.

More specifically, using recent developments in the theory of production, 2 we address the problems related to measuring: (i) real output produced and real input utilized by the private business sector; (ii) produc- 
tivity growth or technical change; (11i) the effects on domestic real output of changes in the terms of trade; and (iv) the impact on final sales to domestic purchasers of changes in the balance of payments deficit in a consistent accounting framework. We illustrate our suggested solutions using U.S. data for the years 1968-82.

Our solution to the problem of measuring real output, real input, productivity, and "welfare" (the combined effect of technical change and changes in the terms of trade) turns out to be numerically very close to the "Divisia" measurement techniques pioneered by Jorgenson and Griliches 11967, 1972] and Christensen and Jorgenson [1970]. Our translog approach however allows us to give very precise interpretations of our indexes, including a decomposition of the indexes into individual comparative static effects -- the impact on the overall index of the change in a set of exogenous variables such as the prices of imports or the prices of exports.

Theoretical development and empirical implementation of these indexes requires recognition of three distinct classes of (net) outputs, and their corresponding prices, produced by the private business sector: (i) sales to domestic purchasers (consumption goods, investment goods, and sales to the government sector); (ii) sales to foreign purchasers (commodity or merchandise exports); and (iii) purchases of foreign inputs (commodity or merchandise imports). We view foreign commodity trade as passing through the private production sector: all commodity exports are produced hy the production sector and all commodity imports enter the private production sector and are combined with transportation, wholesaling, retalling and other inputs before being sold to domestic purchasers. 
This treatment of trade, following that of Burgess [1974], and Kohli [1978], allows us to answer hypothetical questions about internationally traded goods using only production theory, whereas in the traditional paradigm which treats traded goods as perfectly substitutable with a class of domestic goods, a general equilibrium framework is required. Consider a hypothetical increase in the relative price of an exported good between periods $t-1$ and $t$. If other factors remain constant, the economy can divert resources from export production toward domestic goods production and still maintain the previous balance of trade deficit or surplus. Thus the effect of an increase in export price is similar to an increase in total factor productivity; "welfare" increases here in response to changes in trade flows rather than technical change, in the sense that there is an increase in output producible with a given vector of inputs because of an exogenous change. In reverse, if the price of an imported good increases and domestic inputs remain constant, then in order to maintain a balance of trade equilibrium the economy will have to devote more resources to producing exports or cut back on imports. In either case domestic production will have to decrease.

The extensive literature on the problems of adjusting real national income and real domestic product for changes in a country's terms of trade ${ }^{3}$ does not provide any persuasive solutions to the problem of measuring these impacts. Our procedures, however, allow us to determine the size of the required decrease (or increase in the export price case mentioned) using index number theory analogous to the usual productivity measurement framework. Although this 
approach deals only with the private production sector of the economy, this restricted focus allows us to develop index number formalae which are firmly based on production theory and thus which possess well-defined optimality properties. 4

The paper proceeds as follows. In section 2 we outline the translog approach to productivity indexes. Our end result is the same as that obtained by Diewert [1980; 493], but we now have a more satisfactory precise interpretation of the productivity index. In section 3 we define translog real product and real input indexes. Section 4 shows how the translog input, output and productivity indexes may be decomposed into products of individual translog price and quantity effects. These price and quantity effects provide valuable comparative statics type information about the economy's product function. In section 5 we outline the translog production function approach to modeling the effects of changes in the prices of exports and imports and define "welfare" indexes capturing the impacts of both technical change and changes in the terms of trade. In section 6 , we switch our focus from the economy's private domestic product (which includes exports minus imports) to the private production sector's sales to domestic purchasers (which excludes exports minus imports). We rework our translog approach, replacing the product function by the sales function. This allows consideration of the deficit effect, which measures the impact on output produced for domestic purchasers of changes in the economy's balance of trade deficit. In section 7, we outline an alternative nonparameteric approach to the measurement of productivity and to the effects of changes in the terms of trade, which is 
necessary if the private production sector's balance of merchandise trade surplus changes sign going from one period to the next. Finally, in section 8 we illustrate the theory using U.S. data, and in section 9 we provide concluding remarks.

\section{Translog Productivity Indexes}

Suppose that there are $\mathrm{N}_{\mathrm{d}}$ domestic goods, $\mathrm{N}_{\mathrm{x}}$ exported goods, $N_{m}$ imported goods (or $N=N_{d}+N_{x}+N_{m}$ net outputs) produced and utilized by the private production sector of an economy. Suppose in addition, that there are $M$ primary inputs. Denote the aggregate private production sector's set of technologically feasible combinations of net outputs and primary inputs by $\Gamma^{t}$, a subset of $N+M$ dimensional space. Thus if $(y, v) \in \Gamma^{t}$, the $N$ dimensional sional vector of net outputs $\mathrm{y} \equiv\left(\mathrm{y}_{1}, \ldots, \mathrm{y}_{\mathrm{N}}\right)^{\mathrm{T}}$ can be produced by the private production sector if producers can utilize the non-negative $M$ dimensional vector of inputs $\mathrm{v} \equiv\left(\mathrm{v}_{1}, \ldots, \mathrm{v}_{\mathrm{M}}\right)^{\mathrm{T}}>0_{\mathrm{M}} .^{5}$ If $\mathrm{y}_{\mathrm{n}}>0(<0)$, then the $\mathrm{n}^{\text {th }}$ net output is an output (input), netted over all producers in the private production sector •

Define the economy's period t private gross domestic product function or product function $g^{t}$ in brief by:

$$
g^{t}(p, v) \equiv \max _{y}\left\{p \cdot y:(y, v) \varepsilon \Gamma^{t}\right\}
$$

where $\mathrm{p} \equiv\left(\mathrm{p}_{1}, \ldots, \mathrm{p}_{\mathrm{N}}\right)^{\mathrm{T}} \gg \mathrm{o}_{\mathrm{N}}$ is a (hypothetical) positive vector of net out-. put prices that private producers face ${ }^{6}$ and $v>0_{M}$ is a non-negative vector of primary inputs that are (hypothetically) available to producers during period 
t. Thus $g^{t}(p, v)$ is the maximum value of domestic outputs plus exports minus imports (where these goods are priced out at the relevant prices $p_{n}$ in the $p$ vector), given that the vector of primary inputs $v$ is available ${ }^{7}$ and given the period $t$ aggregate technology at set $\Gamma^{t}$. We assume that the technology set $\Gamma^{t}$ is a closed, convex cone, so that the aggregate technology is subject to constant returns to scale. ${ }^{8}$ In this case, $g^{t}(p, v)$ will be a convex and linearly homogeneous function in $\mathrm{p}$, and a concave, nondecreasing and linearly homogenous function in $v$. In fact, under a few additionai reguiarity conditions on $\Gamma^{t}, g^{t}$ will completely characterize the technology set $\Gamma^{t}$, i.e., there is a duality between $\Gamma^{t}$ and $g^{t} \cdot 9$

Let $p^{t} \gg O_{N}$ be the observed price vector for net outputs during period $t$ and let $y^{t}, v^{t}$ be the corresponding vectors of net outputs and primary inputs respectively for period $t$. If producers are competitively profit maximizing during period $t$ and the product function $g^{t}(p, v)$ is differentiable at $\left(\mathrm{p}^{\mathrm{t}}, \mathrm{v}^{\mathrm{t}}\right)$, by Hotelling's Lemma we have the following relationship between $\mathrm{y}^{\mathrm{t}}, \mathrm{p}^{\mathrm{t}}$ and $\mathrm{v}^{\mathrm{t}}$ :

$$
y^{t}=\nabla_{p} g^{t}\left(p^{t}, v^{t}\right)
$$

where $\nabla_{p} g^{t} \equiv\left(\partial g{ }^{t} / \partial p^{1}, \ldots, \partial g^{t} / \partial p^{N}\right)^{T}$ denotes the vector of first order partial derivatives of $\mathrm{g}^{\mathrm{t}}$ with respect to the components of $\mathrm{p}$. Let $\mathrm{w}^{\mathrm{t}} \equiv$ $\left(w_{1}^{t}, \ldots, w_{M}^{t}\right)^{T} \gg O_{M}$ denote the positive vector of input prices that producers face during period t.10 Then by a shadow pricing result that may be found in Diewert $[1974 ; 140], 11$ we have the following relationship between $w^{t}, p^{t}$ and $v_{t}:$ 


$$
w^{t}=\nabla_{v} g^{t}\left(p^{t}, v^{t}\right)
$$

where $\nabla_{\mathrm{v}} \mathrm{g}^{\mathrm{t}}$ is the gradient vector of $\mathrm{g}^{\mathrm{t}}$ with respect to the components of $\mathrm{v}$. We are now ready to define a new family of theoretical productivity indexes that is similar in spirit to the families of output price and output quantity indexes defined by Fisher and Shell [1972] and Samuelson and Swamy [1974]. Let $p \gg 0_{N}$ be a reference net output price vector and let $v \gg 0_{M}$ be a reference primary input vector. Define the period theoretical productivity index depending on $\mathrm{p}, \mathrm{v}$ by:

$$
R^{t}(p, v) \equiv g^{t}(p, v) / g^{t-1}(p, v)
$$

Using definition ( 1$)$, we see that $R^{t}(p, v)$ is the percentage increase in output (valued at the reference prices $p$ ) that can be produced by the period $t$ technology set compared to the period $t-1$ technology set, given that in both cases the private production economy is utilizing the reference primary input vector $\mathrm{v}$. Thus there are an infinite number of theoretical productivity indexes of the form defined by (4): one for each reference price and quantity vector $p, v$.

Two special cases of (4) will be of interest to us:

$$
R_{L}^{t} \equiv g^{t}\left(p^{t-1}, v^{t-1}\right) / g^{t-1}\left(p^{t-1}, v^{t-1}\right) ; R_{P}^{t} \equiv g^{t}\left(p^{t}, v^{t}\right) / g^{t-1}\left(p^{t}, v^{t}\right)
$$

$R_{L}^{t}$ is a Laspeyres type theoretical productivity index which uses period t-1 output prices and primary input quantities as reference prices and quantities, while $R_{P}^{t}$ is a Paasche type productivity index which uses period $t$ reference prices and quantities. The interpretation for both indexes is: 
the percentage increase in private product that has occurred solely due to improvement in technology - or the organization of production -- going from period $t-1$ to period $t$.

Under the assumption of competitive profit maximizing behavior, we may identify the denominator of $R_{L}^{t}$ and the numerator of $R_{P}^{t}$; $1 . e$., we have for all $t$ :

$$
g^{t}\left(p^{t}, v^{t}\right)=p^{t} \cdot y^{t}=w^{t} \cdot v^{t}
$$

The second equality in (6) follows from our constant returns to scale assumption. Our problem in evaluating $R_{L}^{t}$ and $R_{P}^{t}$ is that we cannot evaluate the hypothetical products, $g^{t}\left(p^{t-1}, v^{t-1}\right)$ and $g^{t-1}\left(p^{t}, v^{t}\right)$. However, it turns out that we can precisely evaluate an average of $R_{L}^{t}$ and $R_{P}^{t}$ if we assume that the functional form for $g^{t}$ has the following translog form for all periods $t=0,1, \ldots, T$ under consideration:

$$
\begin{aligned}
\operatorname{lng}{ }^{t}(p, v) \equiv & \alpha{ }_{0}^{t}+\sum_{n=1}^{N} \alpha_{n}^{t} \ln p_{n}+(1 / 2) \sum_{i=1}^{N} \sum_{j=1}^{N} \alpha_{i j} \ln p_{i} \ln p_{j} \\
& +\sum_{m=1}^{M} \beta_{m}^{t} \ln v_{m}+(1 / 2) \sum_{i=1}^{M} \sum_{j=1}^{M} \beta_{i j} \ln v_{1} \ln v_{j}+\sum_{n=1}^{N} \sum_{m=1}^{M} r \ln _{n} \ln v_{m}
\end{aligned}
$$

where $\alpha_{i j}=\alpha_{j i}, B_{i j}=B_{j i}$ and the parameters satisfy various other restrictions that ensure $\mathrm{g}^{\mathrm{t}}$ is linearly homogeneous in $\mathrm{p}$ and $\mathrm{v} .12$ The important thing to note about definition ( 7 ) is that we allow all of the first order parameters of $\mathrm{g}^{\mathrm{t}}$ to depend on $t$; only the second order parameters (the $\alpha_{i j}$, $B_{i j}$ and $\gamma_{n m}$ ) are restricted to be constant over time. Another important point to note is that $g^{t}$ defined by $(7)$ can approximate an arbitrary twice continuously differentiable function to the second order. Hence there is pro- 
bably little loss of generality from an empirical point of view in assuminE that the private product function of our economy under consideration can be adequately represented by the $\mathrm{g}^{\mathrm{t}}$ defined by $(7)$.

\section{Theorem 1:}

Suppose $g^{t}$ and $g^{t-1}$ are defined by $(7)$ and there is competitive profit maximizing behavior in each period. Then the geometric mean of the two productivity indexes defined by (5) is precisely equai to the transiog implicit output index divided by the translog input index between periods $t-1$ and t; i.e.,

$$
\left(R_{L}^{t} R_{P}^{t}\right)^{1 / 2}=a / b c
$$

where $a \equiv p^{t} \cdot y^{t} / p^{t-1} \cdot y^{t-1}$,

$$
\begin{aligned}
& \operatorname{lnb} \equiv \sum_{n=1}^{N}(1 / 2)\left[\left(p_{n}^{t} y_{n}^{t} / p^{t} \cdot y^{t}\right)+\left(p_{n}^{t-1} y_{n}^{t-1} / p^{t-1} \cdot y^{t-1}\right)\right] \ln \left(p_{n}^{t} / p_{n}^{t-1}\right) \text { and } \\
& \operatorname{lnc} \equiv \sum_{m=1}^{M}(1 / 2)\left[\left(w_{m}^{t} v_{m}^{t} / w^{t} \cdot v^{t}\right)+\left(w_{m}^{t-1} v_{m}^{t-1} / w\right.\right. \\
& \left.\left.t-1 \cdot v^{t-1}\right)\right] \ln \left(v_{m}^{t} / v_{m}^{t-1}\right) .
\end{aligned}
$$

Proof:

$$
\begin{aligned}
\left(R_{L}^{t} R_{P}^{t}\right)^{1 / 2} & \left.=\mid g^{t}\left(p^{t-1}, v^{t-1}\right) / g^{t-1}\left(p^{t-1}, v^{t-1}\right)\right]^{1 / 2}\left[g^{t}\left(p^{t}, v^{t}\right) / g^{t-1}\left(p^{t}, v^{t}\right)\right]^{1 / 2} \\
& =\frac{g^{t}\left(p^{t}, v^{t}\right)}{g^{t-1}\left(p^{t-1}, v^{t-1}\right)}\left\{\frac{g^{t}\left(p^{t-1}, v^{t-1}\right)}{g^{t}\left(p^{t}, v^{t}\right)} \frac{g^{t-1}\left(p^{t-1}, v^{t-1}\right)}{g^{t-1}\left(p^{t}, v^{t}\right)}\right\}^{1 / 2} \\
& \left.=\frac{p^{t} \cdot y^{t}}{p^{t-1} \cdot y^{t-1}} \exp \left\{\frac{1}{2} \mid \nabla_{\ln z^{g}}{ }^{t}\left(z^{t}\right)+\nabla_{\ln z} g^{t-1}\left(z^{t-1}\right)\right] \cdot\left[\ln t^{t-1}-\ln z^{t}\right)\right\}
\end{aligned}
$$

using (6) and the translog utility identity in Caves, Christensen and Diewert 
[1982; 1412] where $z^{t T} \equiv\left(p^{t T}, v^{t T}\right)$. The last line simplifies to a/bc using (2) and (3). Q.E.D.

Note that the right hand side of (8) can be evaluated given just price and quantity data for periods $t$ and $t-1$. Thus although we cannot identify the individual productivity indexes, $R_{L}^{t}$ and $R_{P}^{t}$, we can measure their geometric mean very accurately.

The number $b$ defined below ( 8 ) is the translog output price index $P_{0}\left(p^{t-1}, p^{t}, y^{t-1}, y^{t}\right)$ defined by Diewert [1976; 121].13 The number $a / b$ is the implicit translog output quantity index, $\tilde{Q}_{0}\left(p^{t-1}, p^{t}, y^{t-1}, y^{t}\right)$. The number $c$ is the translog input quantity index, $Q_{0}\left(w^{t-1}, w^{t}, v^{t-1}, v^{t}\right)$. Thus (8) may be rewritten as:

$$
\left(R_{L}^{t} R_{P}^{t}\right)^{1 / 2}=\widetilde{Q}_{0}\left(p^{t-1}, p^{t}, y^{t-1}, y^{t}\right) / Q_{0}\left(w^{t-1}, w^{t}, v^{t-1}, v^{t}\right)
$$

The rather remarkable result, (8) or (9), may be derived in an alternative fashion using the quadratic lemma in the presence of discrete variables developed by Denny and Fuss [1983a] [1983b].14

Alternative approaches to the measurement of productivity based on the Malmquist [1953] - Hicks [1981; 256] efficiency index idea may be found in Caves, Christensen and Diewert [1982; 1401-8] and Diewert [1983; 1077-83].

\section{Translog Real Product and Real Input Indexes}

The translog productivity index, (8) or (9), is consistent with traditional concepts of productivity growth measurement; i.e., $\tilde{Q}_{0} / Q_{0}$ represents the growth in output independent of input growth, or "pure" technical change. The next step is to consider the definitions and interpretation of the com- 
ponent indexes of $\left(R_{L}^{t} R_{p}^{t}\right)^{1 / 2}=R^{t}$, the translog (or Divisia) output or product and input quantity indexes $\tilde{Q}_{0}$ and $Q_{0}$.

To define real (i.e., deflated) product, we shall first define an output price deflator. We follow the example of Fisher and Shell [1972], Samuelson and Swamy [1974;588-92] and Diewert [1983; 1055] and define the private business sector's theoretical output price index between periods $t-1$ and $t$ using the reference period $r$ technology set ( $r$ will be set equal to $t$ or $t-1$ later) and using the reference primary input vector $v \gg O_{M}$ as:

$$
P\left(p^{t-1}, p^{t}, v, r\right) \equiv g^{r}\left(p^{t}, v\right) / g^{r}\left(p, v^{t-1}\right)
$$

where $\mathrm{p}^{t} \gg \mathrm{O}_{\mathrm{N}}$ and $\mathrm{p}^{\mathrm{t}-1} \gg \mathrm{O}_{\mathrm{N}}$ are the observed positive (net) price vectors for periods $t$ and $t-1$ respectively. Thus $P\left(p^{t-1}, p^{t}, v^{t-1}, t-1\right)=$ $\mathrm{g}^{t-1}\left(\mathrm{p}^{t}, \mathrm{v}^{t-1}\right) / \mathrm{g}^{t-1}\left(\mathrm{p}^{t-1}, \mathrm{v}^{t-1}\right)$ is the proportional increase in period $t-1$ nominal product if prices of net outputs were changed from period t-l prices to period $t$ prices, but the technology and primary input vectors were held constant at their period t-l levels. This special case of (10) (and one other) will be of particular interest:

$$
P_{L}^{t} \equiv g^{t-1}\left(p^{t}, v^{t-1}\right) / g^{t-1}\left(p^{t-1}, v^{t-1}\right) ; P_{P}^{t} \equiv g^{t}\left(p^{t}, v^{t}\right) / g^{t}\left(p^{t-1}, v^{t}\right)
$$

$P_{L}^{t}$ is a Laspeyres type theoretical output price index which uses the period $t-1$ technology set and the period $t-1$ primary input vector $\mathrm{v}^{t-1}$ as reference quantities, while $\mathrm{P}_{\mathrm{P}}^{t}$ is a Pasche type index which uses the period $t$ reference technology set and quantities.

The following theorem shows that we can calculate the geometric 
mean of $P_{L}^{t}$ and $P_{P}^{t}$ using observable data under some relatively unrestrictive conditions.

Theorem 2 (Diewert [1983; 1062]):

Suppose $g^{t}$ and $g^{t-1}$, the private product functions for periods $t$ and $t-1$, are defined by $(7)$ and there is competitive profit maximizing behavior in each period. Then

$$
\left(P_{L}^{t} P_{P}^{t}\right)^{1 / 2}=P_{0}\left(p^{t-1}, p^{t}, y^{t-1}, y^{t}\right) \equiv b
$$

where $P_{0}\left(p^{t-1}, p^{t}, y^{t-1}, y^{t}\right)$ is the translog output price index which is equal to $b$ defined below (8).

The above theorem suggests that the empirically calculable translog price index $P_{0}\left(p^{t-1}, p^{t}, y^{t-1}, y^{t}\right)$, is an appropriate output price deflator between periods $t-1$ and $t$. We suggest that a good measure of real product growth between period $t-1$ and $t$ is the corresponding translog implicit quantity index $\tilde{Q}_{0}$ defined by:

$$
\tilde{Q}_{0}\left(p^{t-1}, p^{t}, y^{t-1}, y^{t}\right) \equiv p^{t} \cdot y^{t} / p^{t-1} \cdot y^{t-1} P_{0}\left(p^{t-1}, p^{t}, y^{t-1}, y^{t}\right) .
$$

Turning now to the problem of measuring real input, define the theoretical input quantity index between periods $t-1$ and $t$ using the reference period $r$ technology set and the reference output price vector $p \gg O_{N}$ as:

$$
Q\left(v^{t-1}, v^{t}, p, r\right) \equiv g^{r}\left(p, v^{t}\right) / g^{r}\left(p, v^{t-1}\right) \text {. }
$$

As usual, two special cases of (14) are of interest: 


$$
Q_{L}^{t} \equiv g^{t-1}\left(p^{t-1}, v^{t}\right) / g^{t-1}\left(p^{t-1}, v^{t-1}\right) ; Q_{P}^{t} \equiv g^{t}\left(p^{t}, v^{t}\right) / g^{t}\left(p^{t}, v^{t-1}\right) .
$$

The following theorem shows that we can calculate the geometric mean of the unobservable theoretical indexes $Q_{L}^{t}$ and $Q_{P}^{t}$ using the price and quantity data for periods $t$ and $t-1$ under relatively unrestrictive conditions.

Theorem 3:

Suppose $g^{t}$ and $g^{t-1}$ are defined by $(7)$ and there is competitive profit maximizing behavior in each period. Then

$$
\left(Q_{L}^{t} Q_{P}^{t}\right)^{1 / 2}=Q_{0}\left(w^{t-1}, w^{t}, v^{t-1}, v^{t}\right) \equiv c \text { defined below }(8) .
$$

Proof: ${ }^{15}\left(Q_{L}^{t} Q_{P}^{t}\right)^{1 / 2}$

$$
\left.=\left[g^{t-1}\left(p^{t-1}, v^{t}\right) / g^{t-1}\left(p^{t-1}, v^{t-1}\right)\right]^{1 / 2} / g^{t}\left(p^{t}, v^{t}\right) / g^{t}\left(p^{t}, v^{t-1}\right)\right]^{1 / 2}
$$

using definitions (15)

$=\exp \left\{(1 / 2)\left[\nabla_{\ell n v} g^{t-1}\left(p^{t-1}, v^{t-1}\right)+\nabla_{\ell n v} g^{t}\left(p^{t}, v^{t}\right)\right] \cdot\left[\ln v^{t}-\operatorname{lnv}{ }^{t-1}\right]\right\}$ using the Caves, Christensen and Diewert [1982; 1412] translog identity $=c$ using (3) and (6). Q.E.D.

The above theorem suggests that the empirically implementable

$$
\left.0^{t-1} \mathrm{v}_{\mathrm{v}}^{t-1}, \mathrm{v}^{\mathrm{t}}\right) \text {, is an appropriate index }
$$

of real input growth between periods $t-1$ and $t$. We suggest that a good input price deflator between periods $t-1$ and $t$ is the corresponding translog implicit price index $\tilde{\mathrm{P}}_{0}$ defined by:

$$
\tilde{P}_{0}\left(w^{t-1}, w^{t}, v^{t-1}, v^{t}\right) \equiv w^{t} \cdot v^{t} / w^{t-1} \cdot v^{t-1} Q_{0}\left(w^{t-1}, w^{t}, v^{t-1}, v^{t}\right) .
$$


To summarize, we suggest that the private production sector's output price deflator should be defined by (12), the corresponding real product index by (13), the real input index by (16) and the corresponding input price deflator by (17). The result indexes preserve account identities so that the value of inputs will equal the value of outputs in each period. The output price deflator and the input quantity index have nice economic interpretations in terms of theoretical indexes. Finally, if the above system of accounting is followed, our preferrea productivity index defined by $(9)$ in the previous section is simply the ratio of our suggested real product and real input indexes.

\section{Translog Price and Quantity Effects}

In this section, we further decompose our indexes to provide economic interpretations for the components of our output price deflator $P_{0}\left(p^{t-1}, p^{t}, y^{t-1}, y^{t}\right)$ and for the components of our real input index $Q_{0}\left(w^{t-1}\right.$, $\left.w^{t}, v^{t-1}, v^{t}\right)$.

For each net output good $n$, we define the following output price effects $\mathrm{P}_{\mathrm{Ln}}^{\mathrm{t}}$ and $\mathrm{P}_{\mathrm{Pn}}^{\mathrm{t}}$ analogously to the theoretical output price indexes defined by $(11)$ : for $n=1,2, \ldots, N$,

$$
\begin{aligned}
& P_{L n}^{t} \equiv g^{t-1}\left(p_{1}^{t-1}, \ldots, p_{n-1}^{t-1}, p_{n}^{t}, p_{n+1}^{t-1}, \ldots, p_{N}^{t-1}, v^{t-1}\right) / g^{t-1}\left(p^{t-1}, v^{t-1}\right) ; \\
& P_{P n}^{t} \equiv g^{t}\left(p^{t}, v^{t}\right) / g^{t}\left(p_{1}^{t}, \ldots, p_{n-1}^{t}, p_{n}^{t-1}, p_{n+1}^{t}, \ldots, p_{N}^{t}, v^{t}\right) .
\end{aligned}
$$

The indexes $P_{I n}^{t}$ and $P_{P n}^{t}$ provide answers to the following hypothetical comparative statics type question: what is the proportional change in private product that can be attributed to the change in the $\mathrm{n}^{\text {th }}$ output price 
going from period t-l to $t, p_{n}^{t-1}$ to $p_{n}^{t}$, holding constant other prices and primary input availabilities and also holding the technology constant at the period $t-1$ or period $t$ level.

The following counterpart to Theorem 2 (which may be proven in the same manner) shows that we can calculate the geometric mean of the Laspeyres and Paasche price effects for good $n$ using observable price and quantity data for periods $t-1$ and $t$.

Theorem 4:

Suppose $g^{t}$ and $g^{t-1}$ have the translog functional form as in (7) and there is competitive profit maximizing behavior in each period. Then for $n=1$, $\ldots, N$,

$$
\begin{aligned}
& \left(P_{L n}^{t} p_{P n}^{t}\right)^{1 / 2}=b_{n} \text { where } \\
& \ell b_{n} \equiv(1 / 2)\left[\left(p_{n}^{t} y_{n}^{t} / p^{t} \cdot y^{t}\right)+\left(p_{n}^{t-1} y_{n}^{t-1} / p^{t-1} \cdot y^{t-1}\right)\right] \ln \left(p_{n}^{t} / p_{n}^{t-1}\right) .
\end{aligned}
$$

Note that the product of the $b_{n}$ equals the aggregate output price effect defined in Theorem 2; i.e., we have

$$
\prod_{n=1}^{N} b_{n}=b=P_{0}\left(p^{t-1}, p^{t}, y^{t-1}, y^{t}\right)=\left(P_{L}^{t} P_{P}^{t}\right)^{1 / 2}
$$

Thus we may decompose the aggregate price change going from period $t-1$ to $t$ into a product of individual price changes.

Turning now to the input side, for each input $m$, we may define the following input quantity effects $Q_{L m}^{t}$ and $Q_{P m}^{t}$ in the following manner, which is analogous to the theoretical quantity indexes defined by (15): for 
$m=1,2, \ldots, M$,

$$
\begin{aligned}
& Q_{L m}^{t} \equiv g^{t-1}\left(p^{t-1}, v_{1}^{t-1}, \ldots, v_{m-1}^{t-1}, v_{m}^{t}, v_{m+1}^{t-1}, \ldots, v_{M}^{t-1}\right) / g^{t-1}\left(p^{t-1}, v^{t-1}\right) ; \\
& Q_{P m}^{t} \equiv g^{t}\left(p^{t}, v^{t}\right) / g^{t}\left(p^{t}, v_{1}^{t}, \ldots, v_{m-1}^{t}, v_{m}^{t-1}, v_{m+1}^{t}, \ldots, v_{M}^{t}\right) .
\end{aligned}
$$

The indices $Q_{L m}^{t}$ and $Q_{P m}^{t}$ provide answers to the following hypothetical questions: what is the proportional change in private product that can be attributed to the change in the $\mathrm{m}^{\text {th }}$ primary input going from period $t-1$ to period $t, v_{m}^{t-1}$ to $v_{m}^{t}$, holding constant output prices and other primary input availabilities and also holding the technology constant.

The following counterpart to Theorem 3 (which may be proven in the same manner) shows that we can calculate the geometric mean of the Laspeyres and Paasche quantity effects for input $m$ using observable price and quantity data for periods $t-1$ and $t$.

Theor em 5:

Suppose $g^{t}$ and $g^{t-1}$ have the translog functional form as in $(7)$ and there is competitive maximizing behavior in each period. Then for $m=1,2$, $\ldots, M$,

$$
\begin{aligned}
& \left(Q_{L m}^{t} Q_{P m}^{t}\right)^{I / 2}=c_{m} \text { where } \\
& 2 n c_{m} \equiv(1 / 2)\left(w_{m}^{t} v_{m}^{t} / w^{t} \cdot v^{t}\right)+\left(w_{m}^{t-1} v_{m}^{t-1} / w^{t-1} \cdot v^{t-1}\right) / \ln \left(v_{m}^{t} / v_{m}^{t-1}\right) .
\end{aligned}
$$

Note that the product of the $c_{m}$ equals the aggregate input change index defined in Theorem 3; i.e., we have 


$$
\prod_{m=1}^{M} c_{m}=c=Q_{0}\left(w^{t-1}, w^{t}, v^{t-1}, v^{t}\right)=\left(Q_{L}^{t} Q_{P}^{t}\right)^{1 / 2}
$$

Thus we may decompose the aggregate quantity change going from period $t-1$ to $t$ into a product of individual quantity changes or effects. Furthermore, referring back to $(8)$, we see that the theoretical productivity index $\left(R_{R}{ }^{t}\right)^{1 / 2}$ may be written as the nominal product ratio $p^{t} \cdot y^{t} / p^{t-1} \cdot y^{t-1}$ divided by the product of the price effects and quantity effects.

Note that Theorems 4 and 5 may be interpreted as (global) com* parative statics theorems about the private product functions $g^{t-1}(p, v)$ and $g^{t}(p, v)$.

\section{The Translog Product Function Approach to Changes in the Terms of Trade}

We are finally ready to attack the problem of measuring the effects of changes in prices of imported and exported goods on the output of the private business sector of an economy. A possible obvious approach to this problem is to treat changes in the prices of traded goods using the output price effects defined in the previous section. However, it seems useful to define combination theoretical indexes that include the effects of changes in the prices of all internationally traded goods and then see if we can measure special cases of these theoretical indexes with observable price and quantity data.

Recall that at the beginning of section 2, we stated that there were $\mathrm{N}_{\mathrm{d}}$ domestic goods, $\mathrm{N}_{\mathrm{x}}$ exported goods and $\mathrm{N}_{\mathrm{m}}$ imported goods for the private production sector. We now partition our old output price and quantity vectors, $\mathrm{p}^{\mathrm{t}}$ and $\mathrm{y}^{\mathrm{t}}$, into three subvectors of the appropriate dimensions; i.e., taking transposes, we have 


$$
p^{t T} \equiv\left(p_{d}^{t T}, p_{x}^{t T}, p_{m}^{t T}\right) \text { and } y^{t T} \equiv\left(y_{d}^{t T}, y_{x}^{t T},-y_{m}^{t T}\right)
$$

where $p_{d}^{t} \equiv\left(p_{d l}^{t}, \ldots, p_{d N_{d}}^{t}\right)^{T}, p_{x}^{t} \equiv\left(p_{x l}^{t}, \ldots, p_{x N}^{t}\right)_{x}^{T}$ and $p_{m}^{t} \equiv\left(p_{m l}^{t}, \ldots, p_{m N}^{t}\right)^{T}$ are positive period $t$ price vectors for domestic outputs, exports and imports respectively and $y_{d}^{t}, y_{x}^{t}$ and $y_{m}^{t}$ are the corresponding non-negative quantity vectors. Note that the last $N_{m}$ components of the original quantity vector $y^{t}$ are minus the non-negative components of the import quantity vector $y_{m}^{t} \equiv$ $\left(\mathrm{y}_{\mathrm{ml}}^{\mathrm{t}}, \cdots, \mathrm{y}_{\mathrm{mN}}^{\mathrm{t}}\right)^{\mathrm{T}}>\mathrm{O}_{\mathrm{N}_{\mathrm{m}}}$.

We define the following theoretical terms of trade product adjustment indexes in a manner analogous to the theoretical price indexes defined by (18):

$$
\begin{aligned}
& A_{L}^{t} \equiv g^{t-1}\left(p_{d}^{t-1}, p_{x}^{t}, p_{m}^{t}, v^{t-1}\right) / g^{t-1}\left(p_{d}^{t-1}, p_{x}^{t-1}, p_{m}^{t-1}, v^{t-1}\right) ; \\
& A_{p}^{t} \equiv g^{t}\left(p_{d}^{t}, p_{x}^{t}, p_{m}^{t}, v^{t}\right) / g{ }^{t}\left(p_{d}^{t}, p_{x}^{t-1}, p_{m}^{t-1}, v^{t}\right) .
\end{aligned}
$$

The Laspeyres and Paasche adjustment indexes defined by (24) each tell us what the proportional change in domestic product would be if export and import prices changed from $p_{x}^{t-1}, p_{m}^{t-1}$, to $p_{x}^{t}, p_{m}^{t}$, holding constant domestic prices and primary input availabilities and also holding the technology constant.

The following counterpart of Theorem 2 shows that we may calculate the geometric mean of the Laspeyres and Paasche terms of trade adjustment indexes using observable price and quantity data for period $t-1$ and $t$.

\section{Theorem 6:}

Suppose the product functions $g^{t}$ and $g^{t-1}$ have the translog func- 
tional form as in ( 7 ) and there is competitive profit maximizing behavior in each period. Then

$$
\begin{aligned}
& \left(A_{L}^{t} A_{P}^{t}\right)^{1 / 2}=d / e \quad \text { where } \\
& \operatorname{lnd} \equiv \sum_{i=1}^{N}(1 / 2)\left[\left(p_{x i}^{t} y_{x i}^{t} / p^{t} \cdot y^{t}\right)+\left(p_{x i}^{t-1} y_{x i}^{t-1} / p^{t-1} \cdot y^{t-1}\right)\right] \ln \left(p_{x i}^{t} / p_{x i}^{t-1}\right) \text { and } \\
& \ell_{n e} \equiv \sum_{i=1}^{N}(1 / 2)\left[\left(p_{m i}^{t} y_{m i}^{t} / p^{t} \cdot y^{t}\right)+\left(p_{m i}^{t-1} y_{m i}^{t-1} / p^{t-1} \cdot y{ }^{t-1}\right)\right] \ln \left(p_{m i}^{t} / p_{m i}^{t-1}\right)
\end{aligned}
$$

The proof of this theorem follows along the lines of Theorem 3. Our empirically implementable terms of trade adjustment index, d/e, turns out to be (roughly speaking) an index of export prices divided by an index of import prices. The indexes are not quite conventional indexes since the weights, $p_{x i}^{t} y_{x i} / p^{t} \cdot y^{t}$ and $p_{m i} y_{m i} / p^{t} \cdot y^{t}$, do not sum up to one (remember $p^{t} \cdot y^{t}=$ $\left.p_{d}^{t} \cdot y_{d}^{t}+p_{x}^{t} \cdot y_{x}^{t}-p_{m}^{t} \cdot y_{m}^{t}\right)$. Our adjustment index $d / e$ provides a very precise answer to a question which has intrigued national income accountants for 50 years.

The careful reader will be able to show that d/e is also equal to a product of our old output price effects $b_{n}$ defined below (19), where the product is taken over all internationally traded goods.

Suppose we wish to measure the combined effects of technical progress and improvements in the terms of trade, holding all domestic inputs fixed. Such an index might be termed an (output) "welfare" change index. Consider the following family of such indexes: 
(26)

$$
W^{t}\left(p_{d}, v\right) \equiv g^{t}\left(p_{d}, p_{x}^{t}, p_{m}^{t}, v\right) / g{ }^{t-1}\left(p_{d}, p_{x}^{t-1}, p_{m}^{t-1}, v\right)
$$

where $p_{d}$ is a positive vector of reference domestic commodity prices of dimension $\mathrm{N}_{\mathrm{d}}$ and $\mathrm{v}$ is a positive reference vector of primary inputs. Note that $\mathrm{g}^{\mathrm{t}-1}$ is the product function using the period $t-1$ technology set while $\mathrm{g}^{\mathrm{t}}$ uses the period t technology set. As usual, we consider two special cases of (26):

$$
\begin{aligned}
w_{L}^{t} & \equiv g^{t}\left(p_{d}^{t-1}, p_{x}^{t}, p_{m}^{t}, v^{t-1}\right) / g^{t-1}\left(p_{d}^{t-1}, p_{x}^{t-1}, p_{m}^{t-1}, v^{t-1}\right) \text { and } \\
w_{P}^{t} & \equiv g^{t}\left(p_{d}^{t}, p_{x}^{t}, p_{m}^{t}, v^{t}\right) / g^{t}\left(p_{d}^{t}, p_{x}^{t-1}, p_{m}^{t-1}, v^{t}\right) .
\end{aligned}
$$

The following counterpart of Theorem 1 shows that we may calculate the geometric mean of the Laspeyres and Paasche private product welfare indexes using observable data.

Theorem 1: Suppose the product functions $\mathrm{g}^{\mathrm{t}}$ and $\mathrm{g}^{\mathrm{t}-1}$ have the translog functional form as in (7) and there is competitive profit maximizing behavior in each period. Then

$$
\left(W_{L}^{t} W_{P}^{t}\right)^{1 / 2}=(a / b c)(d / e)=\left(R_{L}^{t} R_{P}^{t}\right)^{1 / 2}\left(A_{L}^{t} A_{P}^{t}\right)^{1 / 2}
$$

where $a, b$ and $c$ are defined below (8) and $d$ and $e$ are defined below (25). Thus the "welfare" change index on the left hand side of (28) is equal to the product of our earlier productivity index $\left(R_{L}^{t} R_{P}^{t}\right)^{1 / 2}$ times our terms of trade adjustment factor $\left(A_{L}^{t} A_{P}^{t}\right)^{1 / 2}$. Unfortunately, formula (25) is not the end of the story. There are two conceptual problems with the product terms of trade adjustment indexes defined by (24): (i) since the value of exports minus the value of imports is part of the private business product, the theoretical adjustment indexes do 
not isolate the change in domestic production $\mathrm{p}_{\mathrm{d}} \cdot \mathrm{y}_{\mathrm{d}}$ that could be attributed to changes in export and import prices and (ii) the theoretical indexes defined by (24) do not impose a balance of payments constraint on the private business economy. Thus in the following sections, we take an alternative approach to measuring the effects of changes in the prices of internationally traded goods on domestic production which allows us to consider these problems.

6. The Translog Sales Function Approach to Changes in the Terms of Trade Consider the following function $s^{t}$ defined by: ${ }^{16}$

$$
\begin{gathered}
s^{t}\left(p_{d}, p_{x}, p_{m}, v, v_{0}\right) \equiv \max _{y_{d}, y_{x}, y_{m}}\left\{p_{d} \cdot y_{d}:\left(y_{d}, y_{x},-y_{m}, v\right) \varepsilon \Gamma^{t} ;\right. \\
\left.p_{x} \cdot y_{x}-p_{m} \cdot y_{m}+v_{0}>0\right\} .
\end{gathered}
$$

We call $s^{t}$ the domestic sales function for the period $t$ technology set $\Gamma^{t}$. Besides its dependence on $\Gamma^{t}, s^{t}$ depends on five sets of variables: (i) $p_{d}$, a positive vector of $\mathrm{N}_{d}$ domestic commodity prices; (ii) $p_{x}$, a positive vector of $\mathrm{N}_{x}$ export prices that private domestic producers face (in terms of domestic currency), 17 (iii) $\mathrm{p}_{\mathrm{m}}$, a positive vector of $\mathrm{N}_{\mathrm{m}}$ import prices that private domestic producers face (in terms of domestic currency), 18 (iv) v, a positive vector of $M$ quantities of primary inputs that are available to the private production sector, and $(v)$ a scalar $v_{0}$, a hypothetical balance of merchandise trade deficit that the private production sector is allowed to run. If $v_{0}<0$, then $-v_{0}$ is the trade surplus that the private production sector must produce. The sales function $s^{t}\left(p_{d}, p_{x}, p_{m}, v, v_{0}\right)$ tells us how much domestic output the period $t$ economy can produce (valued at the reference 
prices $p_{d}$ ) given that the vector of primary inputs $v$ is available, exports may be sold at prices $p_{x}$, imports may be purchased at prices $p_{m}$ and the private production sector is allowed to utilize a balance of trade deficit of size $v_{0}$. The sales function is the producer theory counterpart to Woodland's [1980] indirect trade utility function.19

Define the private production sector's period $t$ (net) deficit (surplus if negative) on merchandise trade by

$$
v_{0}^{t} \equiv p_{m}^{t} \cdot y_{m}^{t}-p_{x}^{t} \cdot y_{x}^{t}=\text { value of imports - value of exports. }
$$

When we evaluate the sales function $s^{t}$ at the observed period $t$ arguments, using the assumption of competitive profit maximizing behavior and the constant returns to scale assumption on the technology set $\Gamma^{t}$, we find that 20

$$
s^{t}\left(p_{d}^{t}, p_{x}^{t}, p_{m}^{t}, v^{t}, v_{0}^{t}\right)=p_{d}^{t} \cdot y_{d}^{t}=w^{t} \cdot v^{t}+v_{0}^{t} \cdot
$$

In addition to the above assumptions, we assume that $s^{t}$ is differentiable with respect to its arguments when evaluated at $\mathrm{p}^{\mathrm{t}}, \mathrm{v}^{\mathrm{t}}, \mathrm{v}_{0}^{\mathrm{t}}$. Then adapting the arguments in Diewert [1983; 1092-1094], we find that the first order partial derivatives of $s^{t}$ are equal to the following observable vectors:

$$
\begin{aligned}
& \nabla_{p_{d}} s^{t}\left(p_{d}^{t}, p_{x}^{t}, p_{m}^{t}, v^{t}, v_{0}^{t}\right)=y_{d}^{t}, \\
& \nabla_{p_{x}} s^{t}\left(p_{d}^{t}, p_{x}^{t}, p_{m}^{t}, v^{t}, v_{0}^{t}\right)=y_{x}^{t}, \\
& \nabla_{p_{m}} s^{t}\left(p_{d}^{t}, p_{x}^{t}, p_{m}^{t}, v^{t}, v_{0}^{t}\right)=y_{m}^{t}, \\
& \nabla_{v} s^{t}\left(p_{d}^{t}, p_{x}^{t}, p_{m}^{t}, v^{t}, v_{0}^{t}\right)=w^{t}, \text { and }
\end{aligned}
$$




$$
\nabla_{v_{0}} s^{t}\left(p_{d}^{t}, p_{x}^{t}, p_{m}^{t}, v^{t}, v_{0}^{t}\right)=1
$$

It is evident from (31) and (32) that the deficit $v_{0}$ plays a role which is similar to the role of a primary input: a bigger deficit (holding other things constant) will lead to a bigger equilibrium value of domestic sales. Note that the price of the deficit variable is 1 , the exchange rate. In this section, we plan to rework most of the material presented in the previous 4 sections by using $s^{t}$, the domestic sales function, to replace $\mathrm{g}^{\mathrm{t}}$, our old domestic product function. Thus instead of measuring the effects of technical progress and changes in foreign prices on gross domestic private product, we now want to measure the effects on gross private sales. Since this is the output which actually gets into the hands of domestic purchasers, for short term "welfare" change measurement the sales concept may be more relevant than the product concept.

The counterpart to the theoretical productivity index $R^{t}(p, v)$ defined by $(4)$ is now $R^{t *}\left(p, v, v_{0}\right) \equiv s^{t}\left(p, v, v_{0}\right) / s^{t-1}\left(p, v, v_{0}\right)$ where $p=\left(p_{d}, p_{x}, p_{m}\right)$ as usual. The two special cases of our new family of productivity indexes of interest are:

$$
\begin{aligned}
& R_{L}^{t^{*}} \equiv s^{t}\left(p^{t-1}, v^{t-1}, v_{0}^{t-1}\right) / s^{t-1}\left(p^{t-1}, v^{t-1}, v_{0}^{t-1}\right) \text { and } \\
& R_{P}^{t^{*}} \equiv s^{t}\left(p^{t}, v^{t}, v_{0}^{t}\right) / s^{t-1}\left(p^{t}, v^{t}, v_{0}^{t}\right) .
\end{aligned}
$$

In the remainder of this section, we assume that the functional form for $s^{t}$ is the translog functional form; i.e., $\ln s^{t}\left(p, v, v_{0}\right)$ is defined by the right hand side of $(7)$, except that summations of the form $m=1, \ldots, M$ are 
replaced by $m=0,1, \ldots, M$. This assumes that $v_{0}>0$. If $v_{0}<0$, then we replace $v_{0}$ by $-v_{0} \cdot 21$

We have the following counterpart to Theorem 1 (which may be proven in the same manner, except that (32) is used in place of (2) and (3)):

Theorem 8: Suppose $s^{t-1}$ and $s^{t}$ are translog sales functions, $v_{0}^{t-1}>0$ and $\mathrm{v}_{0}^{\mathrm{t}}>0$, and there is competitive profit maximizing behavior in each period. Then

$$
\begin{aligned}
& \left(R_{L}^{t *} R_{P}^{t *}\right)^{I / 2}=a^{*} / b^{*} c_{0}^{*} c^{*} \equiv R^{t *} \text { where } \\
& a^{*} \equiv p_{d}^{t} \cdot y_{d}^{t} / p_{d}^{t-1} \cdot y_{d}^{t-1}, \\
& \ln b^{*} \equiv \sum_{n=1}^{N}(1 / 2)\left[\left(p_{n}^{t} y_{n}^{t} / p_{d}^{t} \cdot y_{d}^{t}\right)+\left(p_{n}^{t-1} y_{n}^{t-1} / p_{d}^{t-1} \cdot y_{d}^{t-1}\right)\right] \ln \left(p_{n}^{t} / p_{n}^{t-1}\right), \\
& \operatorname{lnc} c_{0}^{*} \equiv(1 / 2)\left[\left(v_{0}^{t} / p_{d}^{t} \cdot y_{d}^{t}\right)+\left(v_{0}^{t-1} / p_{d}^{t-1} \cdot y_{d}^{t-1}\right)\right] \ln \left(v_{0}^{t} / v_{0}^{t-1}\right) \text {, and } \\
& \operatorname{lnc} c^{*} \equiv \sum_{m=1}^{M}(1 / 2)\left[\left(w_{m}^{t} v_{m}^{t} / p_{d}^{t} \cdot y_{d}^{t}\right)+\left(w_{m}^{t-1} v_{m}^{t-1} / p_{d}^{t-1} \cdot y_{d}^{t-1}\right)\right] \ln \left(v_{m}^{t} / v_{m}^{t-1}\right) .
\end{aligned}
$$

Comparing our new empirically implementable productivity index

defined by the right hand side of (34) with our old productivity index defined by $(8)$, we see that if the deficits $v_{0}^{t}$ and $v_{0}^{t-1}$ are small, then $p_{d}^{t} \cdot y_{d}^{t}$ will be close to $p^{t} \cdot y^{t}=w^{t} \cdot v^{t}$ and the term $c_{0}^{*}$ will be close to one, and hence the two productivity indexes will be very close to each other.

If $v_{0}^{t-1}$ and $v_{0}^{t}$ are both negative, then formula (34) is still valid if we cancel out the minus signs in $\ln \left(v_{0}^{t} / v_{0}{ }^{t-1}\right)$ before taking the logarithm. However, if $v_{0}^{t-1}$ and $v_{0}^{t}$ are of opposite sign, then we cannot derive (34). We 
will deal with this opposite sign case in the following section.

Turning now to the price and quantity effects defined in section 4 , we may define analogous Laspeyres and Paasche price effects using the sales function $s$ in place of the product function $g$ as follows:

$$
\begin{aligned}
P_{L n}^{t *} \equiv & s^{t-1}\left(p_{1}^{t-1}, \ldots, p_{n-1}^{t-1}, p_{n}^{t}, p_{n+1}^{t-1}, \ldots, p_{N}^{t-1}, v^{t-1}, v_{0}^{t-1}\right) / s^{t-1}\left(p^{t-1}, v^{t-1}, v_{0}^{t-1}\right) ; \\
& P_{P n}^{t^{*}} \equiv s^{t}\left(p^{t}, v^{t}, v_{0}^{t}\right) / s^{t}\left(p_{1}^{t}, \ldots, p_{n-1}^{t}, p_{n}^{t-1}, p_{n+1}^{t}, \ldots, p_{N}^{t}, v^{t}, v_{0}^{t}\right) .
\end{aligned}
$$

The following counterpart to Theorem 4 (proved in the same manner) shows that we can calculate the geometric mean of the Laspeyres and Paasche price effects for the sales function for good $n$ using observable price and quantity data for period $t-1$ and $t$ :

Theorem 9: Suppose the sales functions $s^{t}$ and $s^{t-1}$ have the translog functional form, $v_{0}^{t} v_{0}^{t-1}>0$, and there is competitive profit maximizing behavior in each period. Then for $n=1, \ldots, N$,

$$
\begin{aligned}
& \left(P_{L n}^{t^{*}} P_{P n}^{t^{*}}\right)^{1 / 2}=b_{n}^{*} \quad \text { where } \\
& \left.\ln b_{n}^{*} \equiv(1 / 2)\left[\left(p_{n}^{t} y_{n}^{t} / p_{d}^{t} \cdot y_{d}^{t}\right)+p_{n}^{t-1} y_{n}^{t-1} / p_{d}^{t-1} \cdot y_{d}^{t-1}\right)\right] \ln \left(p_{n}^{t} / p_{n}^{t-1}\right) .
\end{aligned}
$$

Note that the product of the $b_{n}^{*}$ equals the aggregate output price effect $b^{*}$ which was defined in Theorem 8: i.e.,

$$
\prod_{n=1}^{N} b_{n}^{*}=b^{*},
$$


If $v_{0}^{t}$ and $v_{0}^{t-1}$ are small in magnitude, then the new price effects $b_{n}^{*}$ defined by (36) will be close to the old price effects $b_{n}$ defined by (19).

Our new input quantity effects analogous to the old input quantity effects defined by (21) are:

$$
\begin{aligned}
Q_{L m}^{t *} \equiv & s^{t-1}\left(p^{t-1}, v_{1}^{t-1}, \ldots, v_{m-1}^{t-1}, v_{m}^{t}, v_{m+1}^{t-1}, \ldots, v_{M}^{t-1}, v_{0}^{t-1}\right) / s^{t-1}\left(p^{t-1}, v^{t-1}, v_{0}^{t-1}\right), \\
& Q_{P m}^{t *} \equiv s^{t}\left({ }_{p}^{t}, v^{t}, v_{0}^{t}\right) / s^{t}\left({ }_{p}^{t}, v_{1}^{t}, \ldots, v_{m-1}^{t}, v_{m}^{t-1}, \ldots, v_{M}^{t}, v_{0}^{t}\right) .
\end{aligned}
$$

The following counterpart to Theorem 5 (proven in the same manner except we use (32) in place of (2) and (3)) shows that we can calculate the geometric mean of the Laspeyres and Paasche input quantity effects for the sale function for input $m$ using observable data.

\section{Theorem 10:}

Suppose the sales functions $s^{t}$ and $s^{t-1}$ have the translog functional form, $v_{0}^{t} v_{0}^{t-1}>0$, and there is competitive profit maximizing behavior in each period. Then for $m=1, \ldots, M$,

$$
\begin{aligned}
& \left(Q_{L m}^{t *} Q_{P m}^{t *}\right)^{I / 2}=c_{m}^{*} \quad \text { where } \\
& \qquad n c_{m}^{*} \equiv(1 / 2)\left[\left(w_{m}^{t} v_{m}^{t} / p_{d}^{t} \cdot y_{d}^{t}\right)+\left(w_{m}^{t-1} v_{m}^{t-1} / p_{d}^{t-1} \cdot y_{d}^{t-1}\right)\right] 2 n\left(v_{m}^{t} / v_{m}^{t-1}\right) .
\end{aligned}
$$

Note that the product of the $c_{m}^{*}$ equals the aggregate input quantity effect $c^{*}$ which was defined in Theorem 8 : i.e.,

$$
\prod_{m=1}^{M} c_{m}^{*}=c^{*} .
$$


We may also define Laspayres and Paasche deficit effects as follows:

$$
\begin{aligned}
& Q_{L 0}^{t^{*}} \equiv s^{t-1}\left(p^{t-1}, v^{t-1}, v_{0}^{t}\right) / s^{t-1}\left(p^{t-1}, v^{t-1}, v_{0}^{t-1}\right) \text { and } \\
& Q_{P O}^{t^{*}} \equiv s^{t}\left(p^{t}, v^{t}, v_{0}^{t}\right) / s^{t}\left(p^{t}, v^{t}, v_{0}^{t-1}\right) .
\end{aligned}
$$

The indexes $Q_{L O}^{t^{*}}$ and $Q_{P O}^{t^{*}}$ provide answers to the following hypothetical question: what is the proportional change in private domestic sales that can be attributed to a change in the private sector's balance of trade deficit from $v_{0}^{t-1}$ to $v_{0}^{t}$, holding constant output, export and import prices, and holding constant the technology set and primary input availabilities.

Under the hypothesis of Theorem 10, we have

$$
\left(Q_{L O Q_{P O}^{t *}}^{t *}\right)^{1 / 2}=c_{O}^{*} \equiv Q_{O}^{t *}
$$

where $c_{0}^{*}$ is defined below $(34)$. The results (26), (39) and (42) may be interpreted as global comparative statics theorems, relating to the sales functions $s^{t}$ and $s^{t-1}$. We now define the following theoretical terms of trade sales adjustment indexes in a manner analogous to the old product adjustment indexes defined by (24):

$$
\begin{aligned}
& A_{L}^{t^{*}} \equiv s^{t-1}\left(p_{d}^{t-1}, p_{x}^{t}, p_{m}^{t}, v^{t-1}, v_{0}^{t-1}\right) / s^{t-1}\left(p_{d}^{t-1}, p_{x}^{t-1}, p_{m}^{t-1}, v^{t-1}, v_{0}^{t-1}\right) ; \\
& A_{p}^{t *} \equiv s^{t}\left(p_{d}^{t}, p_{x}^{t}, p_{m}^{t}, v^{t}, v_{0}^{t}\right) / s^{t}\left(p_{d}^{t}, p_{x}^{t-1}, p_{m}^{t-1}, v^{t}, v_{0}^{t}\right) .
\end{aligned}
$$

The following theorem is a counterpart to Theorem 6 . 
Theorem 11:

Suppose the sales functions $s^{t}$ and $s^{t-1}$ have the translog functional form, $v_{0}^{t} v_{0}^{t}>0$, and there is competitive profit maximizing behavior in each period. Then the geometric mean of the Laspeyres and Paasche theoretical terms of trade sales adjustment indexes may be calculated using period $t-l$ and $t$ price and quantity data:

$$
\begin{gathered}
\left(A_{L_{1}}^{t^{*}} A_{P}^{t *}\right)^{1 / 2}=d^{*} / e^{*} \equiv A^{t *} \quad \text { where } \\
\left.\ln d^{*} \equiv \sum_{i=1}^{N}(1 / 2)\left[p_{x i}^{t} y_{x i}^{t} / p_{d}^{t} \cdot y_{d}^{t}\right)+\left(p_{x i}^{t-1} y_{x i}^{t-1} / p_{d}^{t-1} \cdot y_{d}^{t-1}\right)\right] \ln \left(p_{x i}^{t} / p_{x i}^{t-1}\right)
\end{gathered}
$$

and

$$
\ln e^{*} \equiv \sum_{i=1}^{N}(1 / 2)\left[\left(p_{m i}^{t} y_{m i}^{t} / p_{d}^{t} \cdot y_{d}^{t}\right)+\left(p_{m i}^{t-1} y_{m i}^{t-1} / p_{d}^{t-1} \cdot y_{d}^{t-1}\right)\right] \ln \left(p_{m i}^{t} / p_{m i}^{t-1}\right)
$$

Note the close resemblance of (44) to (25). As usual, if the deficits $v_{0}^{t}$ and $v_{0}^{t-1}$ are small in magnitude, our new terms of trade adjustment index $d^{*} / e^{*}$ will be numerically close to our old index $d / e$.

Suppose, as in section 5 , that we wish to measure the combined effects of technical progress and improvements in the terms of trade on domestic sales. Two "welfare" indexes which measure these combined effects are:

$$
\begin{aligned}
& w_{L}^{t *} \equiv s^{t}\left(p_{d}^{t-1}, p_{x}^{t}, p_{m}^{t}, v^{t-1}, v_{0}^{t-1}\right) / s^{t-1}\left(p_{d}^{t-1}, p_{x}^{t-1}, p_{m}^{t-1}, v^{t-1}, v_{0}^{t-1}\right) ; \\
& w_{P}^{t^{*}} \equiv s^{t}\left(p_{d}^{t}, p_{x}^{t}, p_{m}^{t}, v^{t}, v_{0}^{t}\right) / s^{t-1}\left(p_{d}^{t}, p_{x}^{t-1}, p_{m}^{t-1}, v^{t}, v_{0}^{t}\right) .
\end{aligned}
$$


The following counterpart of Theorem 7 shows that we may calculate the geometric mean of the Laspeyres and Paasche private sales welfare indexes using observable data.

Theorem 12: Suppose the sales functions $s^{t}$ and $s^{t-1}$ have the translog functional form, $v_{0}^{t} v_{0}^{t-1}>0$, and there is competitive profit maximizing behavior in each period. Then

$$
\begin{aligned}
\left(W_{L}^{\frac{1}{t *}} W_{P}^{t *}\right)^{1 / 2} & =\left(a^{*} / b^{*} c_{0}^{*} c^{*}\right)\left(d^{*} / e^{*}\right) \equiv w^{\frac{t}{*}} \\
& =\left(R_{L}^{t *} R_{P}^{t^{*}}\right)^{1 / 2}\left(A_{L}^{t^{*}} A_{P}^{t^{*}}\right)^{1 / 2}
\end{aligned}
$$

Thus the "welfare" change index on the left hand side of (46) is equal to the product of our new productivity index $\left(R_{L}^{t^{*}} R_{P}^{t^{*}}\right)^{1 / 2}$ and our new terms of trade adjustment index $\left(A_{L}^{t *} A_{P}^{t^{*}}\right)^{1 / 2}$.

The indexes $W_{L}^{t *}$ and $W_{P}^{t *}$ defined by (45) capture the combined comparative statics effects on private domestic sales of changes in export prices, import prices and technology, holding constant domestic output prices, primary input and the balance of trade deficit. However, we may want our "welfare" index to also capture the effects of a change in the balance of trade deficit; if the deficit increases, there will be an "exogenous" increase in domestic sales that is in some respects similar to a short run increase in total factor productivity. Thus we define the following theoretical "total welfare" change indexes which incorporate the effects of changes in total factor productivity, prices of exports and imports, and changes in the deficit: 


$$
\begin{aligned}
& T_{L}^{t *} \equiv s^{t}\left(p_{d}^{t-1}, p_{x}^{t}, p_{m}^{t}, v^{t-1}, v_{0}^{t}\right) / s^{t-1}\left(p_{d}^{t-1}, p_{x}^{t-1}, p_{m}^{t-1}, v^{t-1}, v_{0}^{t-1}\right) ; \\
& T_{P}^{t *} \equiv s^{t}\left(p_{d}^{t}, p_{x}^{t}, p_{m}^{t}, v^{t}, v_{0}^{t}\right) / s^{t-1}\left(p_{d}^{t}, p_{x}^{t-1}, p_{m}^{t-1}, v^{t}, v_{0}^{t-1}\right) .
\end{aligned}
$$

Theorem 13: Suppose the sales functions $s^{t}$ and $s^{t-1}$ have the translog functional form, $v_{0}^{t} v_{0}^{t-1}>0$, and there is competitive profit maximizing behavior in each period. Then

$$
\begin{aligned}
& \left(T_{L}^{t *} T_{P}^{t^{*}}\right)^{1 / 2}=\left(a^{*} / b^{*} c_{0}^{*} c^{*}\right)\left(d^{*} / e^{*}\right) c_{0}^{*} \equiv T^{t *} \\
& =\left(R_{L}^{t *} R_{P}^{t *}\right)^{1 / 2}\left(A_{L}^{t *} A_{P}^{t *}\right)^{1 / 2}\left(Q_{L O}^{t *}{ }_{Q}^{*} t_{P O}^{*}\right)^{1 / 2} \\
& =\left(W_{L}^{t *} W_{P}^{t *}\right)^{1 / 2}\left(Q_{L O Q}^{t *} Q_{P O}^{*}\right)^{1 / 2} \text {. }
\end{aligned}
$$

Thus the "total welfare" change index on the left hand side of (48) is equal to the "welfare" change index $\left(W_{L}^{t^{*}} W_{P}^{t^{*}}\right)^{1 / 2}$ that holds changes in the deficit constant times the deficit effect index $\left(Q_{L O}^{t *} Q_{P O}^{t^{*}}\right)^{1 / 2}$ defined by (42). Various other decompositions and interpretations of $\left(\mathrm{T}_{\mathrm{L}}^{\mathrm{L}^{*}} \mathrm{~T}_{\mathrm{P}}^{\mathrm{t}^{*}}\right)^{1 / 2}$ are possible, but we leave these to the interested reader.22

The material presented in this section has been contingent on the assumption that the balance of trade deficits have the same sign in adjacent periods. Our translog approach fails if this condition is not satisfied, since $c_{0}^{*}$ is not defined in this case. Empirically, we find that $v_{0}$ does change sign. What then should we do? We address this question in the following section. 


\section{The First Order Approximation Approach}

The translog approach to modelling the sales function fails when $v_{0}$ changes sign going from period $t-1$ to period $t$. In this section, we outline an alternative nonparametric approach to modelling the sales function (which perhaps has a more general validity) which does not fail if $v_{0}$ changes sign.

The basic idea can be explained rather easily. From (32), we can evaluate the first derivatives of the sales function $s^{t}$ at the period $t$ data point. Hence we can form first or der approximations to the two special cases of the various theoretical indexes that always were of interest in the translog approach. We then take the geometric mean of our two linear approximations. The quadratic approximation lemma of Denny and Fuss [1983a] [1983b] leads us to believe that our mean index is accurate to the second order.

Let $u$ apply the above idea to the productivity indexes $R_{L}^{t *}$ and $R_{P}^{t^{*}}$ defined by (33). First order approximations to these theoreticel indexes may be defined by

$$
\text { (49) } \begin{aligned}
\tilde{R}_{L}^{t} \equiv\left[s^{t}\left(p^{t}, v^{t}, v_{0}^{t}\right)\right. & +\nabla_{p} s^{t} \cdot\left(p^{t-1}-p^{t}\right)-\nabla_{v} s^{t} \cdot\left(v^{t-1}-v^{t}\right) \\
& \left.+\nabla_{v_{0}} s^{t} \cdot\left(v_{0}^{t-1}-v_{0}^{t}\right)\right] /\left[s^{t-1}\left(p^{t-1}, v^{t-1}, v_{0}^{t-1}\right)\right]
\end{aligned}
$$


Note that $\widetilde{R}_{L}^{t}$ and $\widetilde{R}_{P}^{t}$ can be numerically evaluated given price and quantity data for periods $t$ and $t-1$. Define

$$
\tilde{R}^{t} \equiv\left(\tilde{R}_{L}^{t} \tilde{R}_{P}^{t}\right)^{1 / 2}
$$

In our empirical work, $\tilde{R}^{t}$ defined by (50) was numerically very close to the translog productivity index defined by the right hand side of $(34), R^{t^{*}}$, for periods when $v_{0}$ did not change sign.

Now apply the same idea to the deficit effects defined by (41). The first order approximations to $Q_{L_{O}}^{t^{*}}$ and $Q_{P O}^{t^{*}}$ and the resulting geometric average are defined by:

$$
\begin{aligned}
\tilde{Q}_{L O}^{t} & \equiv\left[s^{t-1}\left(p^{t-1}, v^{t-1}, v_{0}^{t-1}\right)+\left(\partial s^{t-1} / \partial v_{0}\right)\left(v_{0}^{t}-v_{0}^{t-1}\right)\right] / p_{d}^{t-1} \cdot y_{d}^{t-1} \\
& =\left[1+\left(v_{0}^{t}-v_{0}^{t-1}\right)\left(p_{d}^{t-1} \cdot y_{d}^{t-1}\right)^{-1}\right], \\
\tilde{Q}_{P O}^{t} & \equiv p_{d}^{t} \cdot y_{d}^{t} /\left[s^{t}\left(p^{t}, v^{t}, v_{0}^{t}\right)+\left(\partial s^{t} / \partial v_{0}\right)\left(v_{0}^{t-1}-v_{0}^{t}\right)\right] \\
& =\left[1-\left(v_{0}^{t}-v_{0}^{t-1}\right)\left(p_{d}^{t} \cdot y_{d}^{t}\right)^{-1}\right]^{-1}, \\
\tilde{Q}_{0}^{t} & \equiv\left(\tilde{Q}_{L O}^{t} \tilde{Q}_{P O}^{t}\right)^{1 / 2} .
\end{aligned}
$$

Note that the new first order Laspeyres and Paasche deficit effects and the overall deficit effect $\bar{Q}_{0}^{t}$ are well defined even if $v_{0}^{t-1}$ and $v_{0}^{t}$ are of opposite sign.

First order approximations to the terms of trade sales adjustment indexes defined by (43) and their geometric mean are defined by: 


$$
\begin{aligned}
& \tilde{A}_{L}^{t} \equiv\left[p_{d}^{t-1} \cdot y_{d}^{t-1}+y_{x}^{t-1} \cdot\left(p_{x}^{t}-p_{x}^{t-1}\right)-y_{m}^{t-1} \cdot\left(p_{m}^{t}-p_{m}^{t-1}\right)\right] / p_{d}^{t-1} \cdot y_{d}^{t-1}, \\
& \tilde{A}_{P}^{t} \equiv p_{d}^{t} \cdot y_{d}^{t} /\left[p_{d}^{t} \cdot y_{d}^{t}+y_{x}^{t} \cdot\left(p_{x}^{t-1}-p_{x}^{t}\right)-y_{m}^{t} \cdot\left(p_{m}^{t-1}-p_{m}^{t}\right)\right], \\
& \tilde{A}^{t} \equiv\left(\tilde{A}_{L}^{t} \tilde{A}_{P}^{t}\right)^{1 / 2} .
\end{aligned}
$$

Similar first order approximations to the welfare indexes defined by (45) are (these indexes incorporate changes in productivity and changes in the terms of trade but hold the balance of trade deficit constant):

$$
\text { (53) } \begin{aligned}
\tilde{w}_{L}^{t} & \equiv\left[p_{d}^{t} \cdot y_{d}^{t}+y_{d}^{t} \cdot\left(p_{d}^{t-1}-p_{d}^{t}\right)+w^{t} \cdot\left(v^{t-1}-v^{t}\right)+\left(v_{0}^{t-1}-v^{t}\right)\right] / p^{t-1} \cdot y^{t-1} \\
\tilde{w}_{P}^{t} & \equiv p_{d}^{t} \cdot y_{d}^{t} /\left[p_{d}^{t-1} \cdot y_{d}^{t-1}+y_{d}^{t-1} \cdot\left(p_{d}^{t}-p_{d}^{t-1}\right)+w^{t-1} \cdot\left(v^{t}-v^{t-1}\right)+\left(v_{0}^{t}-v_{0}^{t-1}\right)\right], \\
\tilde{w}^{t} & \equiv\left(\tilde{w}_{L}^{t} \tilde{w}_{P}^{t}\right)^{1 / 2} .
\end{aligned}
$$

Finally, first order approximations to the total welfare change indexes defined by (47) are (these indexes are like the welfare indexes except that they also incorporate changes in the balance of trade deficit):

$$
\begin{aligned}
& \tilde{T}_{L}^{t} \equiv\left[p_{d}^{t} \cdot y_{d}^{t}+y_{d}^{t} \cdot\left(p_{d}^{t-1}-p_{d}^{t}\right)+w^{t} \cdot\left(v^{t-1}-v^{t}\right)\right] / p_{d}^{t-1} \cdot y_{d}^{t-1}, \\
& \tilde{T}_{P}^{t} \equiv p_{d}^{t} \cdot y_{d}^{t} /\left[p_{d}^{t-1} \cdot y_{d}^{t-1}+y_{d}^{t-1} \cdot\left(p_{d}^{t}-p_{d}^{t-1}\right)+w^{t-1} \cdot\left(v^{t}-v^{t-1}\right)\right], \\
& \tilde{T}^{t} \equiv\left(\tilde{T}_{L}^{t} \tilde{T}_{P}^{t}\right)^{1 / 2} .
\end{aligned}
$$

Since our new geometric mean indexes $\widetilde{R}^{t}, \widetilde{Q}_{0}^{t}, \tilde{A}^{t}, \widetilde{W}^{t}$ and $\widetilde{T}^{t}$ do not depend on any functional form assumptions, we call them nonparametric indexes.

Our new nonparametric indexes do not have the nice multiplicative properties that the translog indexes defined in the previous section had: recall (46), 


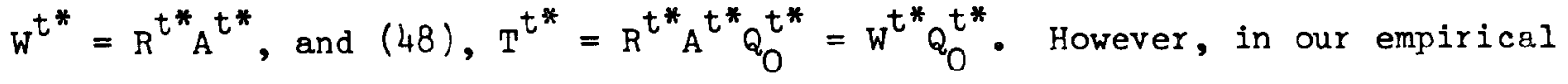
work, we found that our new indexes had the above multiplicative properties to a high degree of approximation. The reason for this close correspondence may be found in the following theorem.

Theorem 14: Regard the translog indexes $R^{t^{*}}, Q^{t^{*}}, A^{t^{*}}, W^{t^{*}}$ and $\mathrm{T}^{t^{*}}$ defined in the previous section by $(34),(42),(44),(46)$ and (48) respectively as functions of their price and quantity arguments for the two periods, $\left(\mathrm{p}^{t-1}, \mathrm{w}^{t=1}, \mathrm{p}^{t}, \mathrm{w}^{t}, \mathrm{y}^{\mathrm{t}=1}\right.$, $\left.\mathrm{v}_{0}^{t-1}, \mathrm{v}^{t-1}, \mathrm{y}^{t}, \mathrm{v}_{0}^{t}, \mathrm{v}^{t}\right) \equiv \mathrm{z}$. (Remember $\mathrm{p}^{\mathrm{t}} \equiv\left(\mathrm{p}_{\mathrm{d}}^{\mathrm{t}}, \mathrm{p}_{\mathrm{x}}^{\mathrm{t}}, \mathrm{p}_{\mathrm{m}}^{\mathrm{t}}\right)$ and $\mathrm{y}^{\mathrm{t}} \equiv\left(\mathrm{y}_{\mathrm{d}}^{\mathrm{t}}, \mathrm{y}_{\mathrm{x}}^{\mathrm{t}},-\mathrm{y}_{\mathrm{m}}^{\mathrm{t}}\right)$, etc.). Regard the nonparametric indexes $\tilde{R}^{t}, \tilde{Q}^{t}, \tilde{A}^{t}, \tilde{W}^{t}$, and $\tilde{T}^{t}$ defined by (50), (51), (52), (53) and (54) respectively, as functions of these same price and quantity arguments $z$. Then the translog indexes differentially approximate the corresponding nonparametric indexes to the second order around any point where the (positive) prices and quantities pertaining to period t-l equal the corresponding prices and quantities pertaining to period $t ; i . e ., R^{t^{*}}=\tilde{R}^{t}$, $\nabla_{z} R^{t *}=\nabla_{z} \widetilde{R}^{t}$ and $\nabla_{z z}^{2} R^{t *}=\nabla_{z z}^{2} \widetilde{R}^{t}$, where $\nabla_{z z}^{2}$ stands for the matrix of second order partial derivatives of the function with respect to all $4 N+4 M+2$ components of $z$ and each function is evaluated at a common point where $p^{t-1}=p^{t}$, $w^{t-1}=w^{t}, y^{t-1}=y^{t}, v_{0}^{t-1}=v_{0}^{t}$ and $v^{t-1}=v^{t}$. Each price and quantity is assumed to be positive except $v_{0}^{t-1}$ and $v_{0}^{t}$ have the same sign.

The proof of the above theorem is by computation. The theorem is similar to results in Diewert [1978] [1983;1099].23

If we use the chain principle to construct our index numbers in an empirical application rather than the fixed base principle, changes in prices 
and quantities will be relatively small going from period to period. Hence, by Theorem 14, the translog indexes defined in the previous section will approximate very closely the nonparameteric indexes defined in this section. The advantage of the translog indexes is that they are exact for a translog sales function which can approximate any sales function to the second order. The nonparameteric indexes have only a formal first order approximation property in terms of approximating an arbitrary sales function, but they numerically approximate the translog indexes to the second order, and hence have an indirect second order approximation property. Moreover, the nonparameteric indexes have a practical advantage over the translog indexes: they are well defined even if the balance of trade deficit changes sign going from one period to the next. We turn now to an empirical application of the index number theory presented above.

\section{Empirical Illustration}

Empirical implementation of the theoretical structure outlined in the previous section requires straightforward calculation of a number of translog or Törnqvist indexes of output, inputs and trade, and combination of these components into the composite productivity or welfare indexes. We have computed these indexes for the United States to illustrate their use for assessing the effects of international interdependence on national economic "welfare".

8.a. Data

The data required to calculate the indexes include price and quantity 
information on national output, capital and labor inputs, exports and imports. We have developed the output, import and export data for 1968-1982 from the National Income and Product Accounts, (U.S. Department of Commerce [1981], [1982], [1983]), and have used real capital stock data constructed by the Bureau of Labor Statistics (U.S. Department of Labor [1983]) and real labor data updated form Jorgenson and Fraumeni [1981], since these series closely approximate our theoretically ideal indexes.

More specifically, we have calculated the value of output, $\left(P^{t}{ }_{Y}^{t}\right)$ as gross domestic business product including tenant occupied housing output, property taxes, and Federal subsidies to businesses, but excluding Federal, State and Local indirect taxes and owner occupied housing. The corresponding price index, $\left(P^{t}\right)$, was computed by cumulating the Business Gross Domestic Product Chain Price Index.

The values of merchandise exports $\left(p_{x}^{t} \cdot y_{x}^{t}\right)$ and imports $\left(p_{m}^{t} \cdot y_{m}^{t}\right)$ were determined by adding the durable and nondurable export and import values, respectively, reported in the National Accounts. Tariff revenues were added to the value of imports. Corresponding prices $\left(P_{x}^{t}\right.$ and $\left.P_{m}^{t}\right)$ were calculated as translog indexes of the components of each measure, and quantities $\left(\mathrm{Y}_{\mathrm{X}}^{\mathrm{t}}\right.$ and $\left.\mathrm{Y}_{\mathrm{m}}^{\mathrm{t}}\right)$ were determined implicitly. For 1967-82, value and price data for nine different types of exports and ten types of imports were available, which were used to compute chain price indexes. For 1960-67, however, only only two components were available; durable and nondurable goods. In this section, the shorter time period was used. For purposes of comparison, however, indexes for 1960-82 were computed and the resulting indexes are presented in the Appendix. 


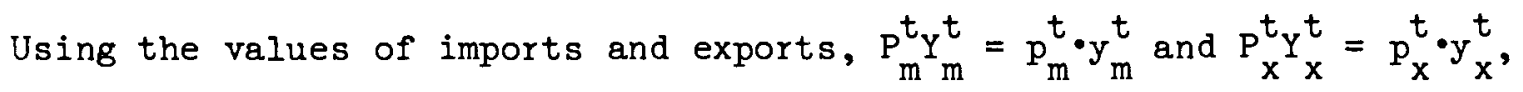
tax adjusted gross domestic private business sales to domestic purchasers, or absorportion, was calculated as $P_{d}^{t} Y_{d}^{t}=P^{t} Y^{t}-P_{X}^{t} Y_{x}^{t}+P_{m}^{t} Y_{m}^{t}$. The corresponding price $\left(\mathrm{P}_{\mathrm{d}}^{t}\right)$ determined by cumulating the gross domestic purchases chain price index from the National Accounts, and the constant dollar quantity $\mathrm{Y}_{\mathrm{d}}^{t}$ was calculated as $Y_{d}^{t}=\left[P^{t} Y^{t}-P_{X}^{t} Y_{x}^{t}+P_{m}^{t} Y_{m}^{t}\right] / P_{d}^{t}$.

Finally, data on prices and expenditures for capital and the wage bill were provided by the Bureau of Labor Statistics Division of Productivity and Technology and an updated labor quantity series was provided by D. Jorgenson and B. Fraumeni. 24

\section{8.b. Empirical Implementation and Results}

The first indexes to consider are those based on the product function given by (1), hereafter denoted the product approsch. Recall that the pure theoretical productivity index $R^{t}(p, v)$ represented by $(4)$ captures only changes in technology between two periods holding all other arguments of $g(\cdot)$, including input levels, constant. $R^{t}$ is measured as a translog or Törnqvist implicit output index $\tilde{Q}_{0}=a / b$ divided by a direct translog input index $Q_{0}=c$, from (8). For empirical implementation, a is calculated directly as the ratio of the value of output $P^{t} Y^{t} / P^{t-1} Y^{t-1}$ and $b$ is calculated as a translog price index of output, where the output identity $P^{t} Y^{t}=P_{d}^{t} Y_{d}^{t}+P_{x}^{t} T_{x}^{t}-P_{m}^{t_{Y}}{ }_{m}^{t}$ is explicitly recognized. Using (13), the implicit output index $\tilde{Q}_{0}$ is calculated as $\mathrm{a} / \mathrm{b}$. The input index, $Q_{0}=c$, in turn, is calculated directly as a translog quantity index of $\mathrm{K}$ and $\mathrm{L}$.

The resulting productivity growth measure $\left(R_{L}^{t} \cdot R_{P}^{t}\right)^{1 / 2}=a / b c$ and its multiplicative components $a, 1 / b$, and $1 / c$ are presented in Table 1. Note 
that this multifactor productivity index captures large drops in productivity in 1970, 1975, 1979-80, and especially 1982. 1975 and 1976 were poor productivity years -- there was a $2 \%$ drop in productivity -- which caused concern in the late 70's about the observed "productivity slowdown". However, the late 1960's were also disappointing and 1977 appeared very strong in terms of productivity growth, indicating that productivity trends cannot be characterized by a unique productivity downturn in 1973. In addition, 1980 exhibited a $2 \%$ productivity decline and 1982 appeared catastrophic with a $6 \%$ drop in productivity. This suggests a trend toward deterioration of productivity growth over time, much of which can be attributed to output fluctuations represented by $a / b$.

To incorporate the effects on U.S. "welfare" of changes in the terms of trade in addition to changes in technical efficiency, the adjustment index $\left(A_{L}^{t} A_{P}^{t}\right)^{1 / 2}=d / e$ must be calculated. Using (25), d/e is computed empirically as the product of the components of export and import price effects.

The translog adjustment index $A^{t}$ for the product approach is reported in Table 1. The index is generally close to 1.0 , since internationally traded goods are such a small proportion of total output, even in the most recent years of the sample. However, in 1974 and 1980 (two energy shock years), increases in the prices of imported goods relative to exported goods were responsible for declines in real output of about $11 / 2 \%$ in each year. With the exception of these two years, the "welfare" Index $\mathrm{w}^{t}$, obtained by multiplying $R^{t}$ and $A^{t}$, does not vary significantly from $R^{t}$; for $a$ relatively closed economy like the U.S., improvements in the terms of trade have a relatively small effect on economic welfare defined in this manner. 
TABLE 1: Translog Productivity Indexes 1968-82

\begin{tabular}{|c|c|c|c|c|c|c|}
\hline Year & a & $1 / b$ & $1 / c$ & $R^{t}=\left(R_{L}^{t} R_{p}^{t}\right)^{1 / 2}$ & $A^{t}=\left(A_{L}^{t} A_{p}^{t}\right)^{1 / 2}$ & $W^{t}=R^{t} A^{t}$ \\
\hline 1968 & 1.09160 & 0.97075 & 0.96793 & 1.02569 & 1.0014 & 1.02583 \\
\hline 1969 & 1.07913 & 0.95930 & 0.96242 & 0.99630 & 1.00032 & 0.99662 \\
\hline 1970 & 1.03610 & 0.95279 & 0.99190 & 0.97918 & 0.99953 & 0.97872 \\
\hline 1971 & 1.07553 & 0.94977 & 0.98468 & 1.00585 & 0.99879 & 1.00463 \\
\hline 1972 & 1.10258 & 0.95385 & 0.96369 & 1351 & 0.99806 & 1.01155 \\
\hline 1973 & 1.12620 & 0.95839 & 0.95305 & 1.02866 & 0.99917 & 1.02781 \\
\hline 1974 & 1.07223 & 0.95500 & 0.98074 & 1.00427 & 0.98568 & 0.98989 \\
\hline 1975 & 1.07595 & 0.90444 & 1.00994 & 0.98280 & 1.00124 & 0.98402 \\
\hline 1976 & 1.11293 & 0.91621 & 0.96939 & 0.98846 & 1.00193 & 0.99036 \\
\hline 1977 & 1.12750 & 0.95053 & 0.96109 & 1.03002 & 0.99532 & 1.02520 \\
\hline 1978 & 1.13456 & $0.9400 \overline{2}$ & 0.95942 & 1.01576 & 0.99737 & 1.01309 \\
\hline 1979 & 1.11534 & 0.93247 & 0.95940 & 0.99779 & 0.99412 & 0.99192 \\
\hline 1980 & 1.07827 & 0.92794 & 0.98228 & 0.98284 & 0.98350 & 0.96662 \\
\hline 1981 & 1.12857 & 0.90035 & 0.97660 & 0.99233 & 1.00264 & 0.99495 \\
\hline 1982 & 1.02477 & 0.91395 & 1.00492 & 0.94120 & 1.00231 & 0.94337 \\
\hline
\end{tabular}

Year

$a^{*}$

$1 / b *$

$1 / c_{0}^{*}$

$1 / c^{*}$

$R^{t^{*}}$

$w^{t *}$

$T^{t *}=W^{t *}{ }^{t *}$

1968

1.09756

0.97074

1.07913

1970

1.03344

1971

1972

1973

1974

1975

1976

1977

1978

1979

1980

1981

1.08265

1.10690

1.11731

1.07834

1.06460

1.12737

1.14295

1.13452

1.11093

1.07334

1.12937

0.95938

0.95283

0.94992

0.95422

0.95864

0.95521

0.90467

0.91651

0.95134

0.94139

0.93388

0.92915

0.90181

1.02735

0.91535

0.96792

$0.99983 \quad 0.96250$

0.99191

0.98472

$0.99523 \quad 0.96398$

1.00866

0.95333

0.98084

1.00991

0.96950

$0.98372 \quad 0.96173$

0.99708

0.95351

$\begin{array}{ll}1.00162 & 0.96025\end{array}$

1.00331

0.98259

0.99742

0.97695

$0.99707 \quad 1.00484$

$\begin{array}{lll}0.99631 & 0.99663 & 0.99680\end{array}$

$\begin{array}{lll}1.01333 & 1.01137 & 1.01622\end{array}$

$\begin{array}{lll}1.02996 & 1.02912 & 1.02028\end{array}$

$\begin{array}{lll}1.00349 & 1.98922 & 1.99593\end{array}$

$\begin{array}{lll}1.02870 & 1.02397 & 1.04092\end{array}$

$1.015391 .01278 \quad 1.01575$

0.99785

0.98316

0.99244

0.94217

0.99211

0.96721

0.99503

0.99050

0.96403

0.94431

0.99760

0.94708 
The second approach to measurement of productivity change and the effects of international trade, the "sales-approach" can also easily be implemented empirically. Recall that using this approach it is possible to determine the impact of changes in the deficit $v_{0}^{t}=P_{m}^{t_{Y}}{ }_{m}^{t}-P_{X}^{t} Y_{x}^{t}$. The productivity measure corresponding to this approach is $\left(R_{L}{ }^{*} R_{P} t^{*}\right)^{1 / 2}=R^{t *}$ listed in the second part of Table 1 . The components of this measure are also reported; $a^{*}, 1 / b^{*}$ and $1 / c^{*}$ are computed as before except that the indexes are weighted by the value of sales. The deficit component cổ is derined below (34) for all periods where the deficit did not change sign. For the five periods where the deficit did change sign, $c_{0}^{*}$ is undefined and so are the corresponding entries for $1 / c_{0}^{*}, R^{t^{*}}, W^{t^{*}}$ and $T^{t^{*}}$. The $R^{t^{*}}$ index corresponds closely to $R^{t}$ defined from the product approach, except that when $v_{0}^{t}$ changes sign, $c_{0}^{t^{*}}$ and thus $R^{t *}$ are undefined. These years are represented by blanks.

$R^{t *}$ can be adjusted by $A^{t *}=d^{*} / e^{*}$ defined similarly to $d / e$ above (but weighted by sales) to generate $\mathrm{w}^{t^{*}}$, which is close to the analogous measure $\mathrm{W}^{\mathrm{t}}$. The sales approach, however, allows us also to consider the deficit effect $c_{0}^{*}$. The impact of this effect was small, with the exception of the year 1977 , where the increase in the trade deficit relative to 1976 was large enough to account for an approximate $1.6 \%$ drop in real output.

In Table 2, we present productivity, adjustment and welfare indexes for the translog product and sales approaches discussed above as well as the first order approximations to the sales approach measures, $\widetilde{R}^{t}, \tilde{A}^{t}, \widetilde{W}^{t}$, and $\tilde{T}^{t}$. It is evident from the Table that the approximations closely correspond to the appropriate translog sales approach indexes for the years where the deficit does 
TABLE 2: Productivity and Welfare Indexes

for the Three Approaches

$\begin{array}{lcccccc}\text { Year } & \tilde{R}^{t} & \mathrm{R}^{t^{*}} & \mathrm{R}^{t} & \tilde{A}^{t} & \mathbf{A}^{t^{*}} & \mathbf{A}^{t} \\ 1968 & 1.02572 & & 1.02569 & 1.00010 & 1.00014 & 1.00014 \\ 1969 & 0.99634 & 0.99631 & 0.99630 & 1.00024 & 1.00032 & 1.00032 \\ 1970 & 0.97941 & & 1.97918 & 0.99934 & 0.99953 & 0.99953 \\ 1971 & 1.00599 & & 1.00585 & 0.99861 & 0.99879 & 0.99879 \\ 1972 & 1.01354 & 1.01333 & 1.01351 & 0.99787 & 0.99807 & 0.99806 \\ 1973 & 1.02903 & 1.02996 & 1.02866 & 0.99852 & 0.99918 & 0.99917 \\ 1974 & 1.00404 & 1.00349 & 1.00427 & 0.98584 & 0.98578 & 0.98568 \\ 1975 & 0.98327 & & 0.98280 & 1.00079 & 1.00124 & 1.00124 \\ 1976 & 0.98833 & & 0.98846 & 1.00190 & 1.00192 & 1.00193 \\ 1977 & 1.02968 & 1.02870 & 1.03002 & 0.99512 & 0.99540 & 0.99532 \\ 1978 & 1.01552 & 1.01539 & 1.01576 & 0.99715 & 0.99743 & 0.99737 \\ 1979 & 0.99830 & 0.99785 & 0.99779 & 0.99358 & 0.99425 & 0.99412 \\ 1980 & 0.98403 & 0.98316 & 0.98284 & 0.98256 & 0.98378 & 0.98350 \\ 1981 & 0.99247 & 0.99244 & 0.99223 & 1.00239 & 1.00260 & 1.00264 \\ 1982 & 0.94218 & 0.94217 & 0.94120 & 1.00236 & 1.00227 & 1.00231\end{array}$

Year

1968

1969

1970

1971

1972

1973

1974

1975

1976

1977

1978

1979

1980

1981

1982 $\tilde{w}^{t}$

1.02582

0.99658

0.97876

1.00458

1.01137

1.02757

0.98991

0.98409

0.99019

1.02463

1.01260

0.99194

0.96713

0.99487

0.94438

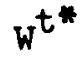

$w^{t}$

1.02583

0.99662

0.97872

1.00463

1.01137

1.02912

0.98922

1.02397

1.01278

0.99211

0.96721

0.99503

0.94431
1.01155

1.02781

0.98989

0.99402

0.99036

1.02520

1.01309

0.99192

0.96662

0.99495

0.94337
$\widetilde{T}^{t}$

1.03139

0.99675

0.97628

1.01147

1.01615

1.02018

0.99591

0.97388

1.00353

1.04085

1.01559

0.99033

0.96395

0.99746

0.94715

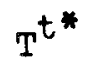

0.99680

1.01622

1.02028

0.99593

1.04092

1.01575

0.99050

0.96403

0.99760

0.94708 
not change sign.

Finally, we summarize some of the information contained in these indexes by average annual growth rates over selected periods in Table 3 . The first two periods to consider represent pre and post OPEC time periods 1968-73 and 1973-77.25 Note that these trends are measured between peak productivity growth years. We also consider growth rates to the end of the sample period; growth rates were calculated both to 1981 and 1982 for comparison since the $198 \overline{2}$ values pull the trend downwar do dramaticaliy.

The overall productivity picture that emerges from these measures is one of cyclical but secularly decreasing productivity growth. There is clearly no unique productivity growth drop post-1973. Consider the pure productivity growth measure based on the product approach, $R^{t}$. The average annual growth rate from 1968 to 1982 is negative; productivity appeared to decrease by $.1 \%$ per year. The breakdown into time periods, however, indicates that this is caused by the last years of the sample. Productivity was observed to grow by .8\%/annum from $1968-73$ and .7\% from 1973 to 1977 -- not a large drop. By contrast, productivity declined by almost $.7 \%$ over the last time periods, 1977 to 1982.

Much of this observed drop is due to the 1982 data. If the growth trend is measured from 1968 to 1981 , the average annual growth rate is . $3 \%$. This also causes the post-1977 growth rate to appear much higher; for this period productivity growth per year is measured as $.5 \%$, a drop from the earlier years but not a substantial drop.

The trends calculated from the $\mathrm{w}^{\mathrm{t}}$ index, the product approach measure adjusted for terms of trade, are lower than those without consideration of 
TABLE 3: Average Annual Growth Rates Selected Periods

$1968-82$

$1973-82$

1968-73

1973-77

1977-82

$1968-81$

1973-81

$1977-81$

$1968-82$

$1973-82$

1968-73

1973-77

$1977-82$

1968-81

$1973-81$

$1977-81$

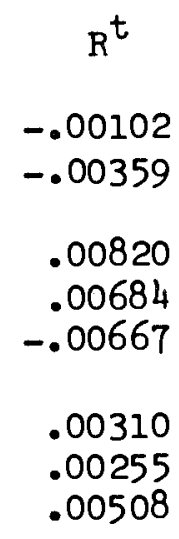

$\tilde{R}^{t}$

$-.00081$

$-.00332$

.00834

.00687

$-.00630$

.00326

.00274

.00400

$$
\begin{gathered}
\mathrm{W}^{\mathrm{t}} \\
-.00369 \\
-.00728 \\
.00753 \\
.00346 \\
-.01081 \\
.00009 \\
-.00179 \\
-.00164
\end{gathered}
$$

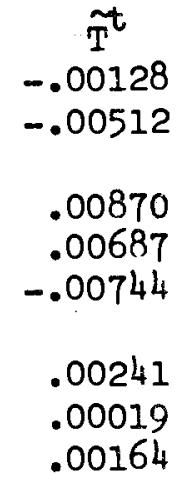


welfare changes from changes in the terms of trade. This is largely a result of the large increases in import prices from the oil shocks -- much of the observed decline is post-1973. This is consistent with the hypothesis that with an increase in import prices relative to export prices, to maintain the same deficit the economy must have less production; an increase in $p_{m}^{t}$ relative to $\mathrm{p}_{x}^{t}$ is analogous to a decrease in total factor productivity. The relative growth rates between time periods are, however, similar to the unadjusted measure $R^{t}$.

The growth rates calculated from the approximation indexes $\tilde{R}^{t}$ and $\tilde{W}^{t}$ based on the sales approach are very similar to those calculated from $R^{t}$ and $W^{t}$. This is as expected since they are measuring the same phenomena, they are just based on slightly different approximation assumptions. Using this approach, however, we may also consider the deficit effect represented by the $\tilde{T}^{t}$ index. Recall that this index reflects exogenous changes in domestic sales from an increase in the deficit that increases "welfare" similarly to short run increases in total factor productivity. It is clear from a comparison of $\tilde{W}^{t}$ to $\tilde{T}^{t}$ that total welfare growth including the deficit effect is higher than that recognizing only the impact of the terms of trade. $\tilde{T}^{t}$ even appears relatively higher in 1977 and 1982 than does the pure productivity measure $\tilde{R}^{t}$. Note also that the growth rate of $\tilde{R}$ and $\tilde{T}$ between 1973 and 1977 is the same. This is, however, a coincidence; the composition of the productivity growth rate over the period is quite different.

It appears, therefore, that adjustments of U.S. productivity measures for terms of trade and deficit effects do not have a substantial impact on 
trends in productivity. They do not, for example, provide a useful rationale for the "productivity slowdown" through the late 1970's and especially the early 1980's. The small effect of trade adjustments is likely the result of the small proportion of international trade carried out in the U.S. relative to total national income. These procedures do, however, provide us with a way to incorporate and assess the effects of international trade flows in our measurement of national real output.

\section{Concluding Remarks}

This paper has focussed on defining index numbers for productivity and "welfare" which are well defined for discrete data, based on production theory, empirically implementable, and decomposable to obtain directly interpretable effects of individual exogenous changes such as changes in technical change and the terms of trade. Using our framework, the effect on welfare of changes in terms of trade can explicitly be developed as analogous to technical change or total factor productivity changes.

We have shown that the translog approach to generating these index numbers results in empirical indexes that are geometric means of hypothetical (unobservable) theoretical indexes. From these empirical indexes we have seen that adjustments to traditional productivity indexes to generate welfare indexes reflecting changes in terms of trade do not substantially change the observed pattern of productivity growth for the United States. We found slightly less growth of total welfare than productivity, resulting mainly from an adverse terms of trade effect but attenuated somewhat by the deficit effect. We would, however, expect the effects to be larger for an economy for which imports and exports were a larger portion of total sales. 


\section{Footnotes}

1. The terms of trade facing an economy is defined as an index of export prices divided by an index of import prices (or the reciprocal of the above).

2. See Caves, Christensen and Diewert [1982], Denny and Fuss [1983] and Diewert [1976, 1978, 1983].

3. See, for example, Nicholson [1960], Rasmussen [1956], Stuvel [1959], Bjerke [1968], Kurabayashi [1971], Scott [1979], Hamada and Iwata [1984] and the references cited in these publications.

4. Our approach is closest in spirit to the work of Gollop [1982]. Unfortunately, he did not distinguish between export prices and prices of domestic commodities, so he could not address the terms of trade adjustment issue.

5. Notation: $\mathrm{v}^{\mathrm{T}}$ denotes the transpose of the column vector $\mathrm{v}$, $o_{M}$ denotes an $M$ dimensional vector of zeros and $w^{T} v=w \cdot v \equiv \sum_{m=1}^{M} w_{m} v_{m} \operatorname{denotes}$ the inner product of the vectors $w$ and $v \cdot v \gg O_{M}$ means each component of $v$ is positive while $v>O_{M}$ means $v>O_{M}$ but $v \neq O_{M^{*}}$

6. Conceptually, these are before consumer tax but after government subsidy prices. If there are taxes on intermediate inputs, then in theory we should distinguish the total production of the good by the originating industry and the total input utilization of the good by other industries. In the latter case, the relevant price is the originating industry price plus the per unit tax on the intermediate good that the using industries must pay. 
Transportation inputs create similar theoretical complications.

7. Primary inputs consist of different grades of labor, capital, inventories, land and other natural resources.

8. Some parts of our growth accounting methodology can be adapted to deal with increasing returns to scale technologies as in Denny, Fuss and May [1981] or Caves, Christensen and Diewert [1982], but then exogenous (econometric) estimates of the degree of returns to scale are required. In this paper, we want our growth accounting methodology to depend only on observable prices and quantities.

9. The product function $\mathrm{g}^{\mathrm{t}}$ was introduced to the economics literature by Samuelson [1953] for the case of sectoral production functions with no joint or intermediate production. In the general case, $\mathrm{g}^{\mathrm{t}}$ was defined by Gorman [1968]. Complete duality theorems between $\mathrm{g}^{\mathrm{t}}$ and $\mathrm{I}^{\mathrm{t}}$ were established by Diewert [1973] and McFadden [1978] .

10. Thus wage rates should include all taxes and fringe benefit components, capital input prices should be ex post user costs of the type constructed by Christensen and Jorgenson [1970], and land user costs should include property taxes.

11. See also Samuelson [1953;20] and Gorman [1968; 153].

12. These conditions may be found in Diewert [1974; 139]. The translog functional form is due to Christensen, Jorgenson and Lau [1971]; the translog product function defined by (7) is due to Diewert [1974] and Russell 
and Boyce [1974].

13. Recall that if good $n$ is an import good, then $y_{n}^{t-1}$ and $y_{n}^{t}$ will be negative and the $\left(p_{n}^{t} / p_{n}^{t-1}\right)$ term in $b$ will be raised to a negative power. Thus the output price index $b$ is essentially a price index of domestic outputs and exports divided by a price index of imports. We follow Jorgenson and Nishimizu [1978] in calling b a translog price index rather than a Tönqvist index.

14. Denny and Fuss $[1983 \mathrm{~b} ; 318]$ also show why a suitable average of first order approximations yields a second order approximation. Their result may provide an intuitive explanation for (8), which essentially says that a certain theoretical index may be approximated to the second order using only first order information.

15. The proof of Theorem 2 is analogous to the proof of Theorem 3. 16. Diewert $[1983 ; 1086]$ called this function the perlod $t$ balance of trade restricted value added function. A similar function was defined by Archibald [1977; 60-61].

17. Thus these prices should include any export subsidies.

18. Thus these prices should include any customs duties, taxes and tariffs.

19. Note that $s^{t}\left(p_{d}, p_{x}, p_{m}, v, v_{0}\right)$ regarded as a function of $p_{d}$ and $v$ has mathematical properties similar to those of $g^{t}(p, v)$, while $s^{t}$ regarded as a function of $p_{x}, p_{m}$ and $v_{0}$ has properties similar to those 
possessed by an indirect utility function. Under our regularity conditions on $\Gamma^{t}, s^{t}$ will be: (i) nondecreasing, concave and linearly homogeneous in $v, v_{0}$, (ii) nondecreasing, convex and linearly homogenous in $\mathrm{p}_{\mathrm{d}}$, (iii) quasiconvex and homogeneous of degree zero in $p_{x}, p_{m}$ and $v_{0}$, (iv) nondecreasing in the components of $\mathrm{p}_{\mathrm{x}}$ and $(\mathrm{v})$ nonincreasing in the components of $\mathrm{p}_{\mathrm{m}}$.

20. We also need to use our assumption that $p_{x}$ and $p_{m}$ are price vectors denominated in units of domestic currency so that exchange rates are unity.

21. The homogeneity and curvature properties of $s^{t}$ will place various restrictions on the parameters (which we will not write out here). Throughout this section, we assume that the quadratic coefficients of the various period specific translog sales functions $s^{t}$ are constant, even though some results (such as those in Theorems 9 and 10) can be derived under weaker conditions (in the sense that some of the quadratic coefficients can depend on time).

22. The term $d^{*} c_{0}^{*} / e^{*}$ correspond to the translog terms of trade adjustment fact or $a_{T}$ defined in Diewert $[1983 ; 1098]$.

23. Following the terminology introduced in Diewert [1978], we might term the translog indexes to be superlative while the non-parametric indexes are pseudosuperlative.

24. The BLS labor quantity series is an unweighted manhours series and hence is unsuitable for our purposes. We wish to thank Mike Harper at BLS and Barbara Fraumeni for their help in providing the updated data series. 


$$
-47-
$$

25. The time periods often considered in the literature include also pre-1965 and 1965-73 instead of 1968-73. To allow for a comparison of the earlier years, productivity measures from the 1960-82 data are considered in the Appendix. 


\section{References}

Archibald, R.B. [1977], "On the Theory of Industrial Price Measurement:

Output Price Indexes," Annals of Economic and Social Measurement 6, 57-72.

Burgess, D.F. [1974], "Production Theory and the Derived Demand for Imports," Journal of International Economics 4, 103-7.

Caves, D.W., L.R. Christensen and W.E. Diewert [1982], "The Economic Theory of Index Numbers and the Measurement of Input, Output, and Productivity," Econometrica 50, 1393-1414.

Christensen, L.R. and D.W. Jorgenson [1970], "U.S. Real Product and Real Factor Input, 1929-1967," The Review of Income and Wealth 16, 19-50.

Christensen, L.R. and D.W. Jorgenson and L.J. Lau [1971], "Confugate Duality and the Transcendental Logarithmic Production Function," Econometrica $39,255-6$.

Denny, M. and M. Fuss [1983a], "The Use of Discrete Variables in Superlative Index Number Comparisons," International Economic Review 24, 419-21.

Denny, M. and M. Fuss [1983b], "A General Approach to Intertemporal and Interspatial Productivity Comparisons," Journal of Econometrics 23, 315-330.

Diewert, W.E. [1973], "Functional Forms for Profit and Transformation Functions," Journal of Economic Theory 6, 284-316.

Diewert, W.E. [1974], "Applications of Duality Theory," pp. 106-71 in M.D. Intriligator and D.A. Kendrick (eds.), Frontiers of Quantitative Economics, Vol. II, Amster dam:

Diewert, W.E. [1976], "Exact and Superlative Index Numbers," Journal of Econometrics $4,114-45$.

Diewert, W.E. [1978], "Superlative Index Numbers and Consistency in Aggregation," Econometrica 46, 883-900.

Diewert, W.E. [1980], "Aggregation Problems in the Measurement of Capital," pp. 433-528 in The Measurement of Capital, D. Usher (eds.), Chicago: The University of Chicago Press.

Diewert, W.E. [1983], "The Theory of the Output Price Index and the Measurement of Real Output Change," pp. 1049-1113 in Price Level Measurement, W.E. Diewert and C. Montmarquette (eds.), Ottawa: Statistics Canada.

Fisher, F.M. and K. Shell [1972], "The Pure Theory of the National Output Deflator," pp. 49-113 in The Economic Theory of Price Indexes by F.M. Fisher and K. Shell, New York: Academic Press. 
Gollop, F.M. [1982], "Growth Accounting in an Open Economy," in Developments in Econometric Analyses of Productivity, A. Dogramaci (ed.), Boston: Klumer Nijhoff.

Gorman, W.M. [1968], "Measuring the Quantities of Fixed Factors," in Value Capital and Growth: Papers in the Honor of Sir John Hicks, J.N. Wolfe, (ed.), Chicago: Aldine Publishing Company.

Greenlees, J.S. and K.D. Zieschang [1984], "Indexes of the Terms of Trade: Theory and Application," preliminary draft, Office of Prices and Living Conditions, U.S. Bureau of Labor Statistics, Washington, D.C.

Hamada, K. and K. Iwata [1984], "National Income, Terms of Trade and Economic Welfare," Economic Journal, forthcoming.

Hicks, J. [1981], Wealth and Welfare, Cambridge, Mass: Harvard University Press.

Jorgenson, D.W. and B.M. Fraumeni [1981], "Relative Prices and Technical Change," in E. Berndt and B. Field (eds.), Modelling and Measuring Natural Resource Substitution: Cambridge, Mass.: MIT Press.

Jorgenson, D.W. and Z. Griliches [1967], "The Explanation of Productivity Change," Review of Economics Studies 34, 249-83.

Jorgenson, D.W. and Z. Griliches [1972], "Issues in Growth Accounting:

A Replay to Edward F. Denison," Survey of Current Business 52:5 (part 2), 65-94.

Jorgenson, D.W. and M. Nishimizu [1982], "U.S. and Japanese Economic Growth, 1952-1974: An International Comparison," The Economic Journal 88, 707-26.

Kohli, U.J.R. [1978], "A Gross National Product Function and the Derived Demand for Imports and Supply of Exports," Canadian Journal of Economics $11,167-82$.

Kurabayashi, Y. [1971], "The Impact of Changes in Terms of Trade on a System of National Accounts: An Attempted Synthesis," The Review of Income and Wealth $17,285-93$.

Lloyd, P.J. and A.G. Schweinberger [1983], "Trade Expenditure and Trade Distance Functions and Applications," mimeo, University of Melbourne, Australia.

Malmquist, S. [1953], "Index Numbers and Indifference Surfaces," Trabajos de Estadistica 4, 209-42.

McFadden, D. [1978], "Cost, Revenue and Profit Functions," pp. 3-109 in Production Economics: A Dual Approach to Theory and Applications, Vol. 1, M. Fuss and D. McFadden (eds.), Amsterdam: North-Holland. 
Nicholson, J.L. [1960], "The Effects of International Trade on the Measurement of Real National Income," Economic Journal 70, 608-12.

Rasmussen, P.N. [1956], Studies in Inter-Sectoral Relations, Amsterdam: North-Holland.

Russell, R.R. and R. Boyce [1974], "A Multilateral Model of International Trade Flows: A Theoretical Framework and Specification of Functional Forms," Institute for Policy Analysis, La Jolla, California.

Samuelson, P.A. [1953], "Prices of Factors and Goods in General Equilibrium," Review of Economic Studies 21, 1-20.

Samuelson, P.A. and S. Swamy [1974], "Invariant Economic Index Numbers and Canonical Duality: Survey and Synthesis," Âmerican Economic Review $64,566-93$.

Scott, M.F.G. [1979], "What Price the National Income?," pp. 163-182 in Economics and Human Welfare: Essays in Honor of Tbor Scitovsky, M.J. Boskin (ed.), New York: Academic Press.

Stuvel, G. [1959], "Asset Revaluation and Terms-of-Trade Effects in the Framework of the National Accounts," Economic Journal 69, 275-92.

U.S. Department of Labor, Bureau of Labor Statistics [1983], Trends in Multifactor Productivity, 1948-81, Bulletin 2178, Washington, D.C. 20402: U.S. Government Printing Office.

U.S. Department of Commerce, Bureau of Economic Analysis [1981], The National Income and Product Accounts of the United States, 1929-76, Statistical Tables, A Supplement to the Survey of Current Business, Washington, D.C. 20402: U.S. Government Printing Office.

U.S. Department of Commerce, Bureau of Economic Analysis [1982, 1983], Survey of Current Business 62:7 (July) and 63:7 (July), Washington, D.C. 20402: U.S. Government Printing Office.

Woodland, A.D. [1980], "Direct and Indirect Trade Utility Functions," Review of Economic Studies 47, 907-26. 
Appendix

This appendix provides indexes analogous to Tables 2 and 3 but including the years 1960-67. These indexes are based on less disaggregated data than the indexes reported in the text; the export and import data include only two components each, durables and nondurables. Therefore, for example, the impact of petroleum price increases, which has an independent effect for the later data sample, is muted.

In general the indexes here indicate similar trends, although the productivity decline over time is more evident in these numbers because of the availability of the earlier data. The growth rate of productivity in the 1960-65 period was $2 \%$ per year, much larger than for any period in the later sample, and the $1965-73$ growth rate was $1 \%$ per annum, compared to $.8 \%$ when considered only from 1968. The 1965-71 numbers are also provided here to emphasize the existence of periods of large productivity declines before 1973, although this is clearly not as disastrous as the average over the 1973-82 period; the $19826 \%$ drop in productivity tends to distort the picture when presented as an average over time. Note, finally, that although the terms of trade and deficit effects adjusted productivity in the same direction as for the later period, earlier in the sample, the effects were not as substantial, resulting in a larger slowdown in "welfare" over time than in productivity. 
TABLE A-1: Productivity and Welfare First-Order Approximations and Translog $1960-82$

$\begin{array}{lcccccc}\text { Year } & \tilde{R}^{t} & R^{t *} & R^{t} & \tilde{A}^{t} & A^{t^{*}} & A^{t} \\ 1960 & 1.01306 & 1.01295 & 1.01862 & 1.00002 & 1.00006 & 1.00006 \\ 1961 & 1.00182 & 1.00184 & 1.00186 & 1.00170 & 1.00165 & 1.00166 \\ 1962 & 1.03201 & 1.03178 & 1.03204 & 1.00040 & 1.00033 & 1.00033 \\ 1963 & 1.01868 & 1.01851 & 1.01867 & 0.99984 & 0.99985 & 0.99985 \\ 1964 & 1.03028 & 1.02991 & 1.03022 & 0.99943 & 0.99951 & 0.99950 \\ 1965 & 1.03086 & 1.03056 & 1.03069 & 1.00098 & 1.00100 & 1.00101 \\ 1966 & 1.02230 & 1.02215 & 1.02217 & 1.00086 & 1.00091 & 1.00091 \\ 1967 & 0.99082 & 0.99084 & 0.99081 & 1.00045 & 1.00046 & 1.00046 \\ 1968 & 1.02551 & 1.02549 & & 1.00030 & 1.00033 & 1.00033 \\ 1969 & 0.99603 & 0.99602 & 0.99602 & 1.00055 & 1.00061 & 1.00061 \\ 1970 & 0.97938 & 0.97916 & & 0.99936 & 0.99955 & 0.99955 \\ 1971 & 1.00601 & 1.00586 & & 0.99860 & 0.99878 & 0.99878 \\ 1972 & 1.01327 & 1.01326 & 1.01307 & 0.99814 & 0.99831 & 0.99833 \\ 1973 & 1.02943 & 1.02912 & 1.03042 & 0.99814 & 0.99873 & 0.99874 \\ 1974 & 1.00500 & 1.00406 & 1.00330 & 0.98486 & 0.98588 & 0.98597 \\ 1975 & 0.98443 & 0.98394 & & 0.99960 & 1.00008 & 1.00009 \\ 1976 & 0.98787 & 0.98802 & & 1.00235 & 1.00237 & 1.00237 \\ 1977 & 1.03257 & 1.03284 & 1.03148 & 0.99236 & 0.99260 & 0.99273 \\ 1978 & 1.01283 & 1.01312 & 1.01281 & 0.99980 & 0.99997 & 0.99997 \\ 1979 & 0.99787 & 0.99735 & 0.99742 & 0.99401 & 0.99456 & 0.99467 \\ 1980 & 0.98027 & 0.97924 & 0.97962 & 0.98645 & 0.98711 & 0.98733 \\ 1981 & 0.98797 & 0.98789 & 0.98808 & 1.00701 & 1.00715 & 1.00703 \\ 1982 & 0.93750 & 0.93661 & 0.93765 & 1.00733 & 1.00722 & 1.00709\end{array}$

$\tilde{W}^{t}$

1960

1961

1962

1963

1964

1965

1966

1967

1968

1969

1970

1971

1972

1973

1974

1975

1976

1977

1978

1979

1980

1981

1982
1.01308

1.00352

1.03242

1.01851

1.02969

1.03186

1.02318

0.99126

1.02582

0.99658

0.97876

1.00458

1.01137

1.02757

0.98991

0.98409

0.99019

1.02463

1.01260

0.99194

0.96713

0.99487

0.94438

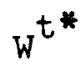

1.01301

1.00348

1.03212

1.01836

1.02940

1.03159

1.02308

0.99130

1.02583

0.99662

0.97872

1.00463

1.01155

1.02781

0.98989

0.98402

0.99036

1.02520

1.01309

0.99192

0.96662

0.99495

0.94337 $w^{t}$

1.01869

1.00352

1.03238

1.01851

1.02971

1.03173

1.02310

0.99127

0.99663

0.99663

1.01137

1.02912

0.98922

1.02397

1.01278

0.99211

0.96721

0.99503

0.94431

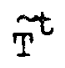

1.00388

1.00162

1.03539

1.01698

1.02653

1.03610

1.02569

0.99129

1.03139

0.99675

0.97628

1.01147

1.01615

1.02018

0.99591

0.97388

1.00353

1.04085

1.01559

0.99033

0.96325

0.99746

0.04715

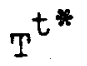

1.00388

1.00162

1.03539

1.01698

1.02654

1.03611

1.02570

0.99129

0.99680

1.01622

1.02028

0.99593

1.04092

1.01575

0.99050

0.96403

0.99760

0.94708 
TABLE A-2: Average Annual Growth Rates Selected Periods

\begin{tabular}{lcc} 
& \multicolumn{1}{c}{$\mathrm{R}^{\mathrm{t}}$} & \multicolumn{1}{c}{$\mathrm{W}^{\mathrm{t}}$} \\
$1960-65$ & .02092 & .02133 \\
$1965-71$ & -.00053 & -.00058 \\
$1965-73$ & .01027 & .01012 \\
$1973-77$ & .00760 & .00346 \\
$1973-81$ & .00173 & -.00179 \\
$1973-82$ & -.00478 & -.00728
\end{tabular}

$\begin{array}{lccc} & \tilde{R}^{t} & \tilde{W}^{t} & \tilde{T}^{t} \\ 1960-65 & .02111 & .02151 & .02008 \\ 1965-71 & -.00045 & -.00060 & .00144 \\ 1965-73 & .01040 & .01011 & .01172 \\ 1973-77 & .00786 & .00328 & .00687 \\ 1973-81 & .00203 & -.0019 & .00019 \\ 1973-82 & -.00443 & -.00727 & -.00512\end{array}$

